\title{
ESTUDO DAS PRECIPITAÇÕES PLUVIAIS MENSAIS NO MUNICIPIO DE BANANEIRAS - PB, ATRAVÉS DE REGRESSÃO PERIÓDICA
}

\author{
JOSE WELLINGTHON DOS SANTOS \\ Engenheiro Agrônomo
}

Orientador: Prof. Dr. CLÓVIS POMPÍLIO DE ABREU

Dissertação apresentada à Escola Superior de Agricultura "Luiz de Queiroz", da Universidade de São Paulo, para obtenção do título de Mestre em Agronomia. Área de Concentração: Estatística e Experimentação Agronômica.

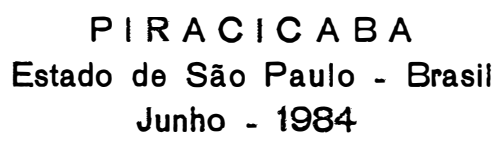


Aos meus pais

DEDICO

Aos meus irmãos

OFERESO 


\section{AGRADECIMENTOS}

A Deus pela minha existência.

Ao Dr. Clóvis Pompilio de Abreú, professor do Departamento de Matemática e Estatística da Escola Superior de Agricul tura "Luiz de Queiroz", pela orientação e amizade.

Ao Dr. Izaias Rangel Nogueira, pelo incentivo e sabedoria.

Ao Dr. Cássio Roberto de Melo Godoi, pela versão do testo pa ra inglês.

Ao Professor Lourival Ferreira Cavalcante do CCA/UFPB e ao Engo Agro Erasmo Rocha Lucena, pelo estimulo sempre demonstrado.

Ao Dr. Hermano Vaz de Arruda, pelas sugestões dadas para rea lização deste trabalho.

Ao Dr. Humberto de Campos, Professor e Chefe do Departamento de Matemática e Estatistica da ESALQ, pelos ensinamentos e apoio recebido durante a realização deste curso.

Ao Dr. Dēcio Barbin, Professor do Curso de Estatística e Experimentação Agronómica, Felos ensinamentos e amizade durante o curso.

Ao Professor João José de 0liveira Filho, Chefe do Departa mento de Ciências Fundamentais e Sociais do CCA / UFPB, pe 10 incentivo e apoio para realização deste curso. 
Aos demais professores do Departamento de Matemática da ESALQ, pelos ensinamentos e dedicação.

A coordenadoria de Aperfeiçoamento de pessoal de nível Superior (CAPES), pela bolsa de estudo concedida.

A srta. Maria Izalina Ferreira Alves e familia, pelo apoio e assistência.

Aos colegas do curso de pós-graduação, pelo espírito de solidariedade e companheirismo.

A todos aqueles, que de uma forma ou de outra souberam me inspirar, incentivar, ajudar e compreender, para que este trabalho pudesse ser realizado. 


\section{INDICE}

Pāgina

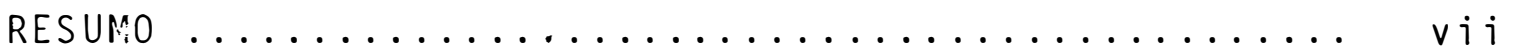

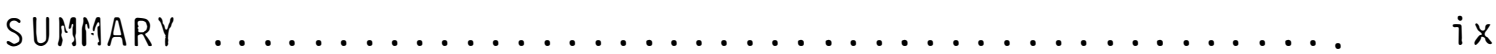

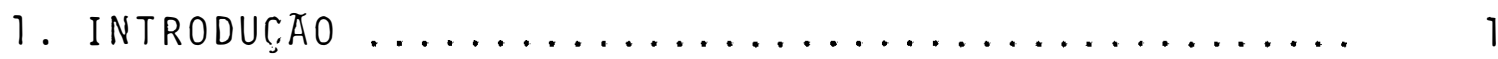

2. REVISAOO DE. LITERATURA $\ldots \ldots \ldots \ldots \ldots \ldots \ldots \ldots \ldots \ldots \ldots$

3. MATERIAL E METODOS ..................... 7

3.1. Material ....................... 7

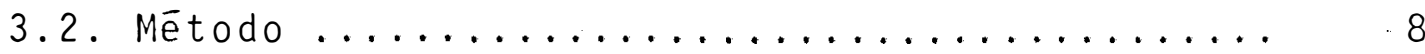

3.2.1. Desenvolvimento teórico $\ldots \ldots \ldots \ldots \ldots$

3.2.2. Modelo matemático .......................... 12

3.2.3. Estimativas dos paràmetros, suas variāncias e covariāncias ............ 18

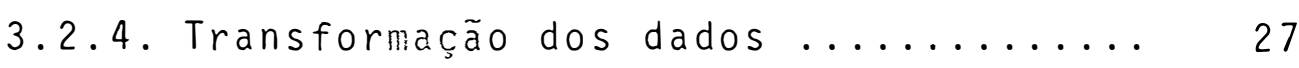

3.2.5. Anālise ce variāncia ............... 29

3.2.5.1. Teste de normalidade ....... 29

3.2.5.2. Quadros c'e anālise de variāncia ................. 32

3.2.6. Intervalos de confiança para os paràme tros estimados ............... 38

3.2.7. Equação de regressão $\ldots \ldots \ldots \ldots \ldots \ldots .38$

4. PESUltAdDOS E DISCUSSAO $\ldots \ldots \ldots \ldots \ldots \ldots \ldots \ldots \ldots$ 
4.1. Estimativas das Precipitações Mensais para o Periodo Anual (Janeiro a Dezenibro) ......... 40 4.1.1. M’odelo matemático ................ 41

4.1.2. Estimativa dos parāmetros .......... 42

4.1.3. Anālise de variāncia .............. 43

4.1.3.1. Teste de norralidade ...... 43

4.1.3.2. Quadros de anālise de variāncia ................. 44

4.1.4. Variāncia dos parāmetros estimados ... 47

4.1.5. Intervalos : confiança .......... 47

4.1.6. Equação ce regressão ............. 48

4.1.7. Representação gräfica ........... 50

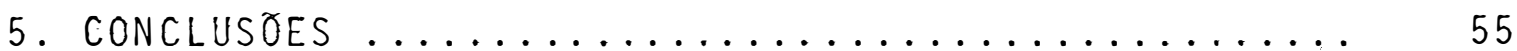

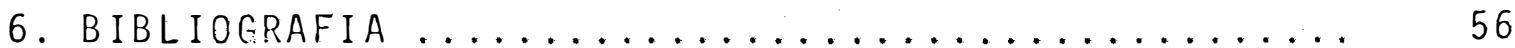

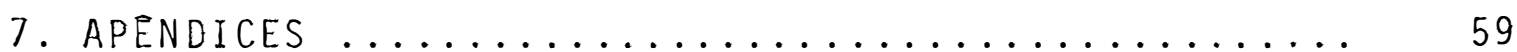




\title{
ESTUDO DAS PRECIPITAÇOES PLUVIAIS MENSAIS NO MUNICIPIO DE BANANEIRAS - PB, ATRAVES DE REGRESSAOO PERIODICA
}

\author{
Autor: José Wellingthon dos Santos \\ Orientador: Dr. Clóvis Pompílio de Abreu
}

\section{RESUMO}

Neste trabalho aplicou-se a regressao periōdica aos valores mensais de chuvas, referentes ao municipio de Bananeiras - PB, perfazendo um total de 47 anos, durante 0 período de 1912 a 1958.

Tendo em vista as exigēncias do modelo metemático, os dados originais, em milimetros, foram ajustados para meses de 30 dias e, posteriormente foi aplicada a transfor mação $x^{0,325}$, visando à uniformização das variāncias.

As anālises estatísticas foram feitas no compu tador eletrónico, IBM-1130, do Departamento de Matemática e Estatistica da ESALQ/USP.

Na anālise de variāncia foi verificada a estabilidade de cada componente harmönico referentes aos contrastes lineares $\bar{p}_{j}$ e $\bar{q}_{j}$. Foi feita a anălise conjunta das ampli tudes $\bar{a}_{k}$ e verificou-se que a $\hat{a}_{1}$ ou seja, a onda anual é respon sável por $96,29 \%$ da variação total.

Determinou-se intervalos de confiança para os 
contrastes $\left(p_{j}\right.$ e $\left.q_{j}\right)$ e para as amplitudes $a_{j}$, referentes aos componentes harmónicos que fazem parte da equação de regressão.

São apresentados os gräficos das ondas senoidais significativas, da sintese dessas ondas e da equação de regressão obtida.

A partir dos dados transformados com uma série de 47 anos foi obtida a seguinte equação de regressão:

$$
\hat{y}_{t}=3,8348+1,5034 \operatorname{sen}(30 t+297,6635)^{\circ}+0,2593 \operatorname{sen}(60 t+358,2369)^{0}
$$

Aproximadamente $99,15 \%$ da variação das precipitações pluviais mensais no município de Bananeiras - PB, $\bar{e}$ explicada pelo modelo. 


\title{
A STUDY ON THE MONTHLY RAINFALL MEASUREMENTS IN BANANEIRAS (PARAIBA COUNTY), THROUGH PERIODIC REGRESSION
}

\begin{abstract}
Author: Josē Wellingthon dos Santos Adviser: Dr. Clóvis Pompīio de Abreu
\end{abstract}

SUMMARY

In this work the periodic regression was applied on the monthly rainfall measurements in Bananeiras - PB, county, in a period of 47 years, from 1912 to 1958.

In view of the requirements of the mathematical model, the original data in milimiters were adjusted to 30 day month and, afterwards, the $x^{0,325}$ transformation was applied to get variance homogeneity

The statistical analyses were elaborated in the IBM-1130 Eletronic Computer belonging to the Department of Mathematics and Statistics of ESALQ/USP.

In the analysis of variance the stability of each on of the harmonic component was verified with respect to the linear contrasts $\hat{p}_{j}$ and $\bar{q}_{j}$. The pooled analysis of the range $\hat{a}_{k}$ was made and $\hat{a}_{1}$, the annual wave, was responsible for $96,29 \%$ of the total variation.

Confidence interval were determined for the 
contrasts $\left(p_{j}\right.$ and $\left.q_{j}\right)$ and for the range $a_{j}$, with respect to the harmonic components belonging to the regression equation. The Graphs of the significant annual waves, of the sinthesis of these waves abd of the regression equation were obtained.

Considering the transformed data the with a sucession of 47 years following regression equation was ob tained:

$$
\bar{y}_{t}=3,8348+1,5034 \operatorname{sen}(30 t+297,6635)^{\circ}+0,2593 \operatorname{sen}(60 t+358,2369)^{0}
$$

Approximately $99,15 \%$ of the variation in the monthly rainfall in Bananeiras - PB, county was explained by the model. 


\section{IHTRODUCCAO}

Um dos principais fatores responsāveis pelas baixas produtividades agrícolas é sem dūvida, a instabilidade pluviométrica, especialmente na região Nordeste onde é registrada a ocorrência de secas que prejudicam sobremaneira a agricultura ali desenvolvida. Sabe-se que as produções agrícolas são elementos probabilísticos no sentido de que elas de pendem entre outros fatores, das variāveis climáticas, tais como quantidade total de chuva, distribuição pluviomētrica, temperatura e umidade relativa do ar.

Não obstante, a exploração de determinadas cuI turas è mais dependente do curso anual de precipitação que do volume de àgua caído anualmente. Portanto, com o estudo da distribuição da precipitação é possível delimitar-se o período crîtico predominante na região e, tem-se condições de fornecer elementos informativos que visem reduzir as consequências causadas pela seca, quer pelo emprego da irrigação ou pe 
10 estabelecimento de culturas mais adaptadas ao regime pluviométrico.

Assim, é de grande valia uma estimativa das quantidades mensais de chuvas, baseada em dados de anos anteriores. Desta forma, o homem sentiu a necessidade de estudar o problema, fazendo simulações matemáticas que descrevem parāmetros do tempo, com a finalidade de prever o comportamento das distribuições probabilísticas dos elementos climáticos, es pecialmente a precinitacão.

No municipio de Bananeiras (PB), embora as alturas pluviométricas diārias venham sendo tomadas desde 1912, não existe nenhum estudo feito a seu respeito.

- O presente trabalho visa, através de um estudo das precipitações mensais naquele município, a auxiliar os téc nicos em planejamento agrícola e engenharia rural, no sentido de se obter um aproveitamento mais racional da água na agri cultura.

Admitindo-se a precipitação mensal um fenōmeno cíclico, aconselha-se o emprego da regressão periódica também conhecida por anālise harmónica em seu estudo. Desta forma, pretende-se a obtenção de uma equação interpretativa do fenómeno. 


\section{REVISATO DE LITERATURA}

CONRAD e POLLAK (1950) utilizaram a anālise har mônica na interpretação de fenômenos climatológicos, exemplificando o método em dois casos, onde o primeiro foi considera do o curso anual, e o segundo o diārio, determinando as equações de regressão que representaram o fenómeno em questão.

BROOKS e CARRUTHERS (1953) afirmaram que cer tos eventos no universo, principalmente aqueles em conexão com os movimentos dos corpos celestes, se repetem sistematica mente após um perīodo de tempo fixo e assim sua ocorrência po de ser prevista precisamente.

BLISS (1958) apresentou um excelente trabalho sobre anālise harmónica aplicada à biologia e climatologia, no qual justificou o método, relatando que muitas vezes os dados não se adaptam a uma regressão polinomial, devido ao fato de seguirem uma tendência periódica. Disse ainda, que se os dados mudam simetricamente durante o ciclo estudado a curva do seno: 


$$
r_{j}=a_{0}+a_{1} \cos (c \cdot j)+b_{1} \operatorname{sen}(c \cdot j) \text {, represen- }
$$

ta bem o fenómeno em estudo, em caso contrārio, mais termos hormōnicos são adicionados, até que o ajuste desejado seja encontrado.

AMARAL (1968) fez um estudo bem detalhado a respeito de anālise harmōnica, exemplificou aplicando a dados pluviométricos (precipitações mensais em Pelotas (RS), 1900 a 1951) e em Morro Velho (MG), 1855 a 1951). No 19 caso ostrés primeiros componentes harmōnicos (ondas anual, semestral e quadrimestral) foram significativos enquanto que no 20 caso apenas o lọ componente harmónico (onda anual) foi significati vo.

ANDERSON (1971) apresentou a teoria sobre funções periōdicas. Demonstrou como calcular os componentes de regressão e como efetuar os testes de significāncia e coefi ciente de correlação para os componentes harmónicos, fornecen do a base para um estudo completo sobre análise rarmónica.

DUARTE e BARBIN (1975) estudaram atravēs da anālise harmōnica os dados de infecção de ferrugem alaranjada do cafeeiro na zona da mata (MG) aplicaram as transformações preconizadas por Blis e Van Der Plank, concluiram que para am bas as transformações a curva do seno representa bem o fenóme no e, que o mīnimo de infecção ocorre em junho e o máximo em dezembro.

THIEBAUT (1976) estudou atravēs da anāilise har mōnica, as precipitações pluviais mensais num período 
de 50 anos no município de Viçosa (MG). Considerou trés períodos, seco, chuvoso e anual, chegou a conclusão que viçosa possui um período seco e um chuvoso bem definidos e, também que o período chuvoso é responsāvel por $86,02 \%$ das quantida des de chuvas anuais.

PEREIRA (1978) fez uma aplicação de regressão periōdica a dados pluviométricos mensais no municīpio de Grajaú (M.A.). Determinou uma equação de regressão que mostra a ocorréncia de um māximo de chuvas no mēs de março e um mỉni mo em julho.

FELTRIN (1980) utilizou a anālise harmōnica, aplicada a valores mensais, de chuvas referentes ao municipio de Bandeirante. (PR) num total de 48 anos (1930 a 1977). Traba Thou com trés períodos (anual, seco e chuvoso), concluiu que Bandeirante apresenta um período seco (abril a setembro) e um periodo chuvoso (outubro a março) bem definidos, sendo o $\bar{u}$ timo responsāvel por $69,40 \%$ da precipitação anual e, para o período chuvoso, a equação de regressão estimada explica 100\% das variações devidas a meses e estima-se um máximo de chuvas durante o mès de janeiro.

COELHO (1980) utilizando a anālise harmōnica a dados de produção de citrus no municĩpio de Limeira (SP) no período de 1970 a 1978, verificou que as ondas de 2,25 e 3 anos são as de maior importāncia.

DUARTE (1981) aplicou a anāitise harmōnica a dados de pércentagens de incidência da ferrugem alaranjada do 
cafeeiro no Estado de Minas Gerais. Concluiu que o máximo de infestação da ferrugem se dā predominantemente no més de junho e o minimo em dezembro. Deduziu as somas de quadrados e os componentes de variância de um modelo matemático para a realização da anālise harmōnica conjunta. 


\section{MATERIAL E METODOS}

\subsection{Material}

os dados de precipitação pluvial, foram obtidos do mapa pluviométrico do Nordeste, publicado pelo Departą mento Nacional de Obras Contra as Secas (BRASIL, 1369).

As observações referem-se às precipitações men sais do municipio de Bananeiras - PB, localizado a $522 \mathrm{~m}$ de altitude, latitude de 6045'11" S e longitude 35037'42" W.G., durante 47 anos, no período de 1912 a 1958, tomadas em milímetros e ajustadas para meses de 30 dias. De acordo com AMARAL (1968) este procedimento consiste na multiplicação da pre cipitação mensal pelo fator $30 / 31$ nos meses de 31 dias, por $30 / 29$ nos meses de fevereiro dos anos bissextos e $30 / 28$ nos meses de fevereiro nos anos não bissextos.

Para as anālises estatisticas dos dados, utili zou-se o computador IBM-1130, do Departamento de Matemática e 
Estatística da Escola Superior de Agricultura "Luiz de Queiroz", da Universidade de São Paulo.

\subsection{Métodos}

A metodologia usada basaia.se aproximadamente no trabalho de FELTRIN (1980), a para maior faciliuade é apresen tada a seguir.

3.2.1. Desenvolvimento teórico

Uma função $f(t)$ ē periōdica de perīodo $T \neq 0$, se para todo $t$, ocorrer:

$f(t) \equiv f(t \pm T),-\infty<t<\infty$, ou ainda

$f(t) \equiv f(t \pm n T)$, com $-\infty<t<\infty$ e $n= \pm 1, \pm 2, \ldots$

As funções trigonométricas sen $t$ e $\cos t$ são funções periōdicas de períodos $2 \pi$, ou seja:

$\operatorname{sen}(t \pm n 2 \pi)^{0}=\operatorname{sen} t^{0}, n= \pm 1, \pm 2, \ldots$

$\cos (t \pm n 2 \pi)^{0}=\cos t^{0}, n= \pm 1, \pm 2, \ldots$

A função representada, pela série trigonométrica de Fourier,

$$
f(t)=a_{0}+\sum_{j=1}^{\infty} a_{j} \cdot \operatorname{sen}\left(j \theta t+A_{j}\right)
$$


é periódica de período $T$, onde $\theta=2 \pi / T$, sendo $\theta$ chamado velo cidade angular.

$$
\begin{gathered}
\text { Desenvolvendo-se }(1) \text {, tem-se: } \\
f(t)=a_{0}+a_{1} \operatorname{sen}\left(\theta t+A_{1}\right)+a_{2} \operatorname{sen}\left(2 \theta t+A_{2}\right)+\ldots+ \\
+a_{j} \operatorname{sen}\left(j \theta t+A_{j}\right)+\ldots
\end{gathered}
$$

o componente harmônico senoidal com frequēncia angular $\theta_{j}=j \Theta \bar{e}$ o j-ésimo harmônico da função periōdica. 0 primeiro harmōnico, também é chamado onda fundamental, e tem o mesmo perĩodo e a mesma frequéncia que a função.

os coeficientes $a_{j}\left(a_{j}>0\right)$ e $A_{j}\left(0<A_{j}<2 \pi\right)$ são denominados respectivamente, amplitude harmōnica e àngulo fase.

Desenvolvendo o seno da soma para cada um dos harmônicos em (2), tem-se:

$$
\begin{aligned}
f(t)=a_{0} & +a_{1}\left(\operatorname{sen} \theta t \cos A_{1}+\operatorname{sen} A_{1} \cos \theta t\right)+ \\
& +a_{2}\left(\operatorname{sen} 2 \theta t \cos A_{2}+\operatorname{sen} A_{2} \cos 2 \theta t\right)+\ldots+ \\
& +a_{j}\left(\operatorname{sen} j \theta t \cos A_{j}+\operatorname{sen} A_{j} \cos j \theta t\right)+\ldots
\end{aligned}
$$

fazendo

$$
\begin{aligned}
a_{1} \operatorname{sen} A_{1}= & P_{1} \\
a_{2} \operatorname{sen} A_{2}= & P_{2} \\
\ldots & \ldots \\
a_{j} \operatorname{sen} A_{j}= & P_{j} \\
\ldots & \ldots
\end{aligned}
$$$$
a_{1} \cos A_{1}=q_{1}
$$$$
a_{2} \cos A_{2}=q_{2}
$$$$
\text { ... } \quad \ldots
$$$$
a_{j} \cos A_{j}=q_{j}
$$ 
e substituindo-se estes valores em ( 3 ), tem-se:

$$
\begin{aligned}
f(t)=a_{0} & +q_{1} \operatorname{sen} \theta t+p_{1} \cos \theta t+ \\
& +q_{2} \operatorname{sen} 2 t+p_{2} \cos 2 t+\ldots+ \\
& +q_{j} \operatorname{sen} j \theta t+p_{j} \cos j \theta t+\ldots
\end{aligned}
$$

Para o j-ésimo harmōnico, tem-se:

$$
p_{j}=a_{j} \operatorname{sen} A_{j} \text { e } q_{j}=a_{j} \cos A_{j}
$$

Portanto;

$$
\begin{aligned}
& a_{j}{ }^{2}=p_{j}{ }^{2}+q_{j}{ }^{2} \\
& \operatorname{Tg} A_{j}=\frac{p_{j}}{q_{j}}
\end{aligned}
$$

ou ainda:

$$
\begin{aligned}
& a_{j}=\left|\sqrt{p_{j}^{2}+q_{j}^{2}}\right| \\
& A_{j}=\operatorname{arctg}\left(\frac{p_{j}}{q_{j}}\right)
\end{aligned}
$$

Os parâmetros $p_{j}, q_{j}, a_{j}$ e $A_{j}$ são representa dos graficamente na figura 1. 
11.

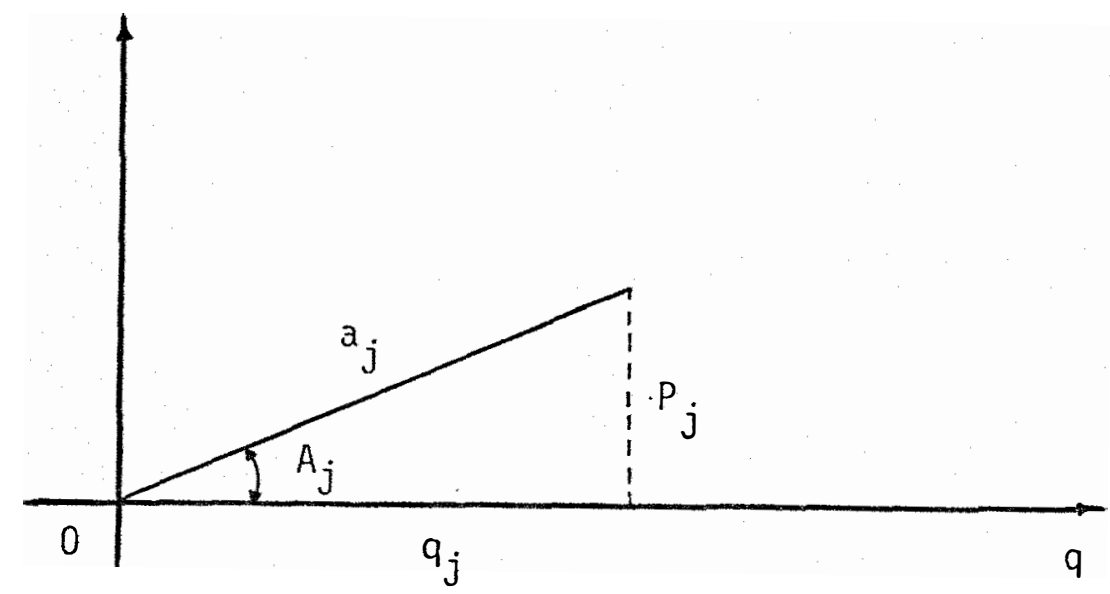

Figura 1 - Parāmetros de j-ēsimo harmōnico.

onde:

$a_{j}=$ amplitude das ondas superpostas;

$A_{j}=$ àngulos fases medidas em graus ou radianos.

O diagrama da Figura 2 adaptado por CONRAD e POLLAK (1950) mostra como determinar os àngulos fases. As com binações dos sinais de $p_{k}$ e $q_{k}$ pelas quais os àngulos fases podem ser determinados são:
a) $+q+p$;
b) $+q-p$;
c) $-q-p$;
d) $-q+p$.

Através das combinações tem-se os seguintes ân gulos fases: 

a) $A++=A$
A, no I quadrante;
b) $\mathrm{At-}=1800-\mathrm{A}$
A, no II quadrante;
c) $\mathrm{A}-\mathrm{-}=1800+\mathrm{A}$
A, no III quadrante;
d) $\mathrm{A}-+=3600-\mathrm{A}$
A, no IV quadrante;

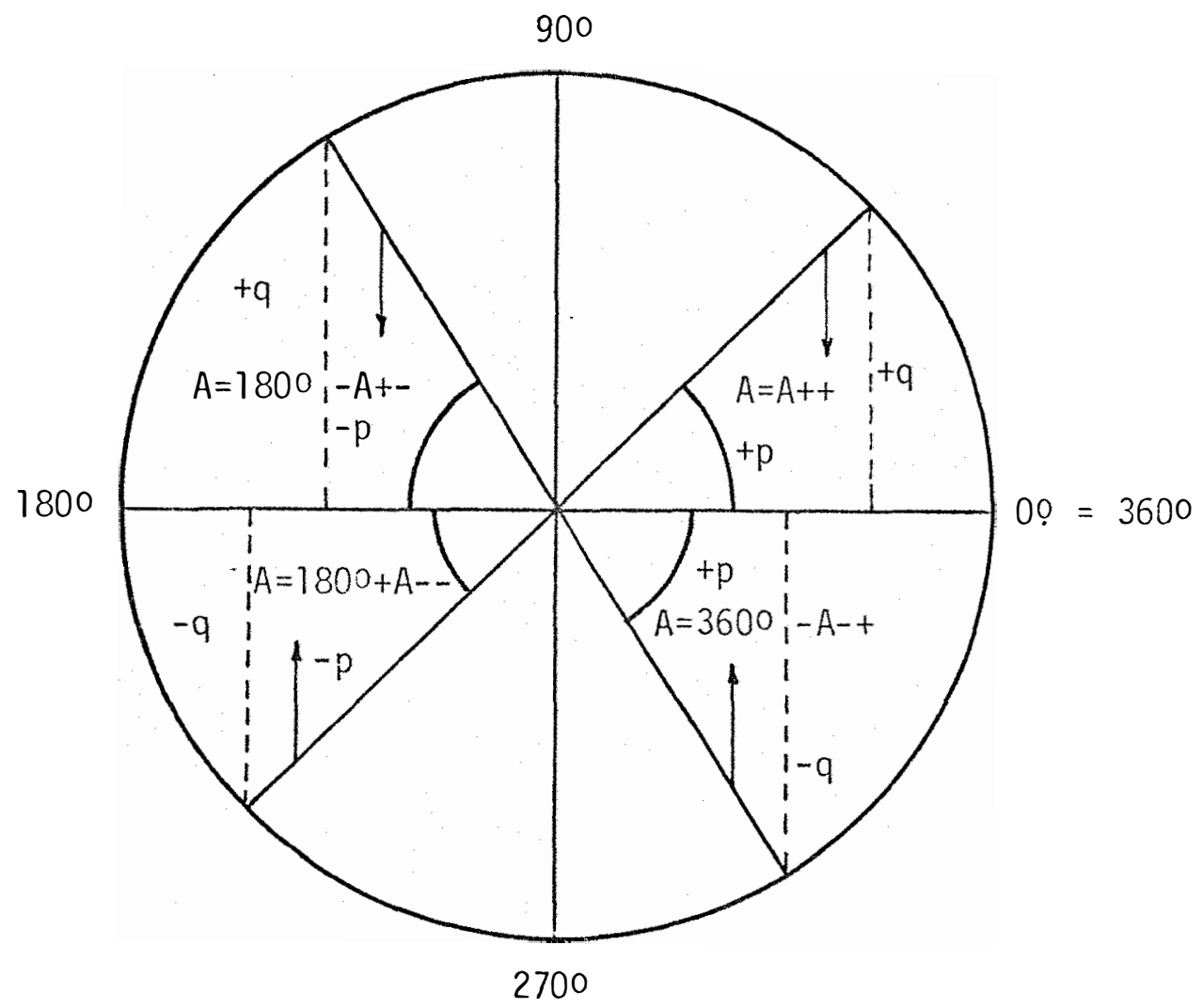

Figura 2 - Diagrama para determinação de àngulo fase.

\subsubsection{Modelo matemático}

Sejà Y ${ }_{t}$ a precipitação mensal observada para $t=1,2, \ldots, T$, onde $t$ representa os meses em que foram tomadas as medidas, e T é o comprimento do perĩodo a ser estudado. 
0 modelo a ser utilizado, proveniente da série de Fourier, é o seguinte:

$$
y_{t}=a_{0}+\sum_{j=1}^{k} a_{j} \operatorname{sen}\left(j t+A_{j}\right)+e_{t}
$$

onde:

$$
\begin{aligned}
a_{0}= & \text { média geral } \bar{Y} ; \\
k= & \text { maior inteiro que não supera } T / 2 ; \\
a_{j}= & \text { amplitude do j-ésimo componente harmónico; } \\
A_{j}= & \text { àngulo fase do j-ésimo componente harmónico: } \\
e_{t}= & \text { efeito residual referente a t-ésima obscrváçaci } \\
& e_{t} \sim N\left(0, \sigma^{2}\right)
\end{aligned}
$$

Desenvolvendo o seno da soma em (9), obtém-se:

$$
y_{t}=a_{0}+\sum_{j=1}^{k}\left(a_{j} \operatorname{sen} A_{j} \cos j \theta t+a_{j} \cos A_{j} \operatorname{sen} j \theta \dot{\tau}\right)+e_{t}
$$

fazendo em (10),

$$
\begin{aligned}
& p_{j}=a_{j} \operatorname{sen} A_{j} \\
& q_{j}=a_{j} \cos A_{j} \\
& y_{t}=r_{t}-a_{0}
\end{aligned}
$$

de tal modo que:

$$
a_{j}=\left|\sqrt{p_{j}{ }^{2}+q_{j}{ }^{2}}\right|, \quad j=1,2, \ldots,(k-1)
$$




$$
a_{k}=\left|\sqrt{p_{k}^{2}+q_{k}^{2}}\right|
$$

Para o caso de T impar e,

$$
a_{k}=\left|\sqrt{p_{k}^{2}}\right|=p_{k}
$$

Para o caso de $T$ par,

$$
A_{j}=\operatorname{arctg}\left(\frac{P_{j}}{q_{j}}\right)
$$

0 modelo matemático passa a ser apresentado sob a forma,

$$
y_{t}=\sum_{j=1}^{k}\left(p_{j} \cos j \theta t+q_{j} \operatorname{sen} j \theta t\right)+e_{t}
$$

Para o caso de T impar, e

$$
y_{t}=\sum_{j=1}^{k-1}\left(p_{j} \cos j \theta t+q_{j} \operatorname{sen} j \theta t\right)+p_{k} \cos k \theta t+e_{t}
$$

para o caso de $T$ par.

Desenvolvendo-se (18) e (19), tem-se respecti-

vamente:

$$
\begin{aligned}
y_{t}= & p_{1} \cos \theta t+p_{2} \cos 2 \theta t+\ldots+p_{k} \cos \theta t+ \\
& q_{1} \operatorname{sen} \theta t+q_{2} \operatorname{sen} 2 \theta t+\ldots+ \\
& q_{k} \operatorname{sen} k \theta t+e_{t}
\end{aligned}
$$

para o caso T impar, e 


$$
\begin{aligned}
y_{t}=p_{1} \cos \theta t & +p_{2} \cos 2 \theta t+\ldots+p_{(k-1)} \cos (k-1) \theta t+ \\
& +p_{k} \cos k \theta t+q_{1} \operatorname{sen} \theta t+q_{2} \operatorname{sen} 2 \theta t+ \\
& +\ldots+q_{(k-1)} \operatorname{sen}(k-1) \theta t+e_{t}
\end{aligned}
$$

para o caso $T$ par.

$$
\text { o sistema de equações pode ser representado ma }
$$
tricialmente por:

$$
y=X \beta+\varepsilon
$$

onde:

$$
\begin{aligned}
& T_{T}^{Y_{1}}=\text { vetor das observações } y_{t} ; \\
& T_{T-1}^{X}=\text { matriz dos coeficientes; } \\
& T-1_{T}^{B}=\text { vetor dos parâmetros } p_{j} \text { e } q_{j} ; \\
& T_{T}^{E}=\text { vetor dos erros aleatórios. }
\end{aligned}
$$

Assim, tem-se:

$$
Y=\left[\begin{array}{c}
y_{1} \\
y_{2} \\
\cdot \\
\cdot \\
y_{T}
\end{array}\right]
$$




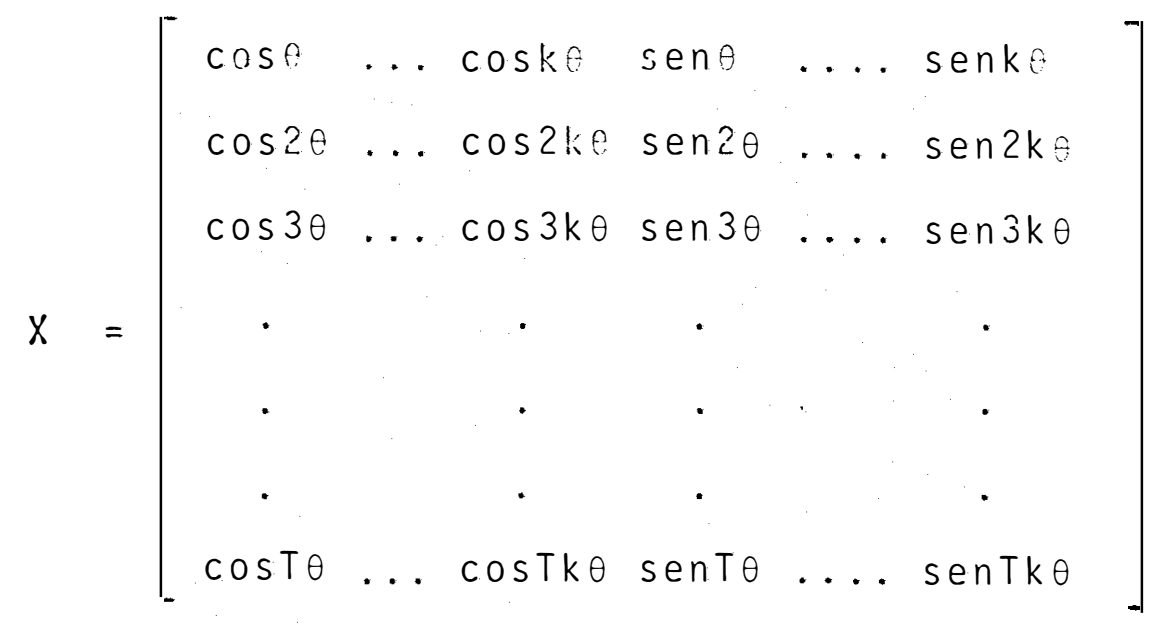

quando $T$ é impar, e,

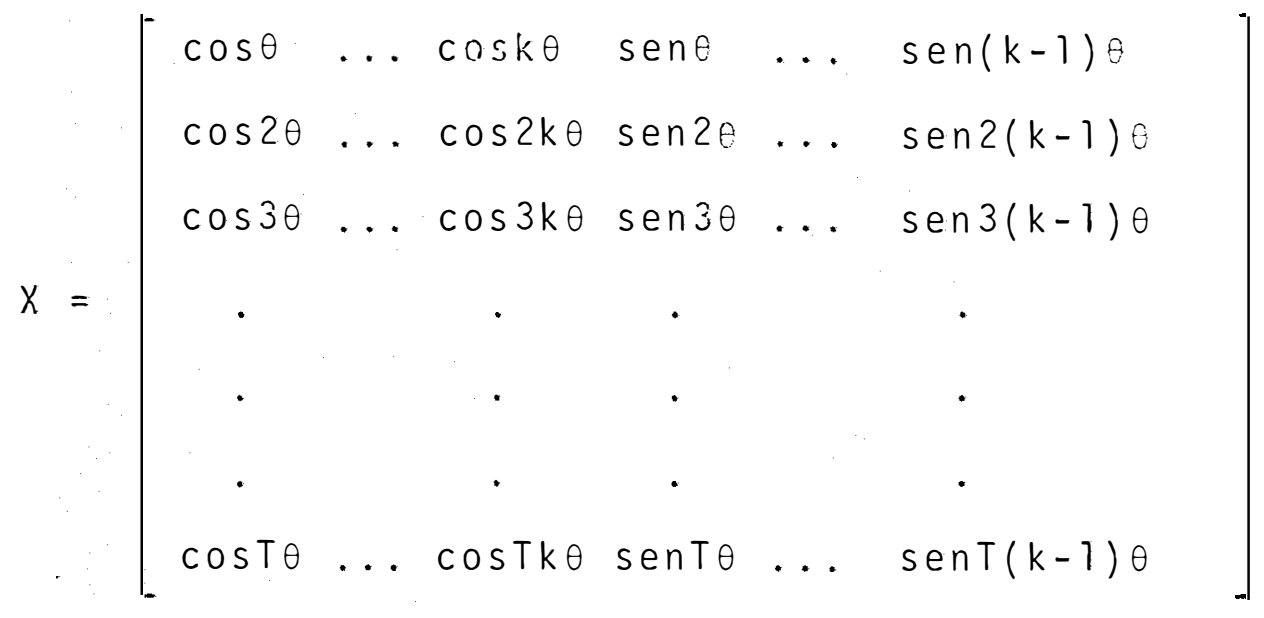

quando $T$ é par. 
$B=\left[\begin{array}{c}p_{1} \\ p_{2} \\ p_{3} \\ \vdots \\ \vdots \\ p_{k} \\ q_{1} \\ q_{2} \\ q_{3} \\ v_{k} \\ q_{k}\end{array}\right]$

quando $T \bar{e}$ impar

$B=\left[\begin{array}{c}p_{1} \\ p_{2} \\ p_{3} \\ \cdot \\ \cdot \\ p_{k} \\ q_{1} \\ q_{2} \\ q_{3} \\ \cdot \\ \cdot \\ q(k-1)\end{array}\right]$

quando $T$ é par: 
$\varepsilon=\left[\begin{array}{c}e_{1} \\ e_{2} \\ e_{3} \\ \vdots \\ e_{T}\end{array}\right]$

3.2.3. Estimativas dos paràmetros, suas variāncias e covariāncias

Pelo método dos quadrados minimos chega-se à solução do sistema de equações normais,

$$
\bar{B}=\left(X^{\prime} X\right)^{-1} X^{\prime} Y,
$$




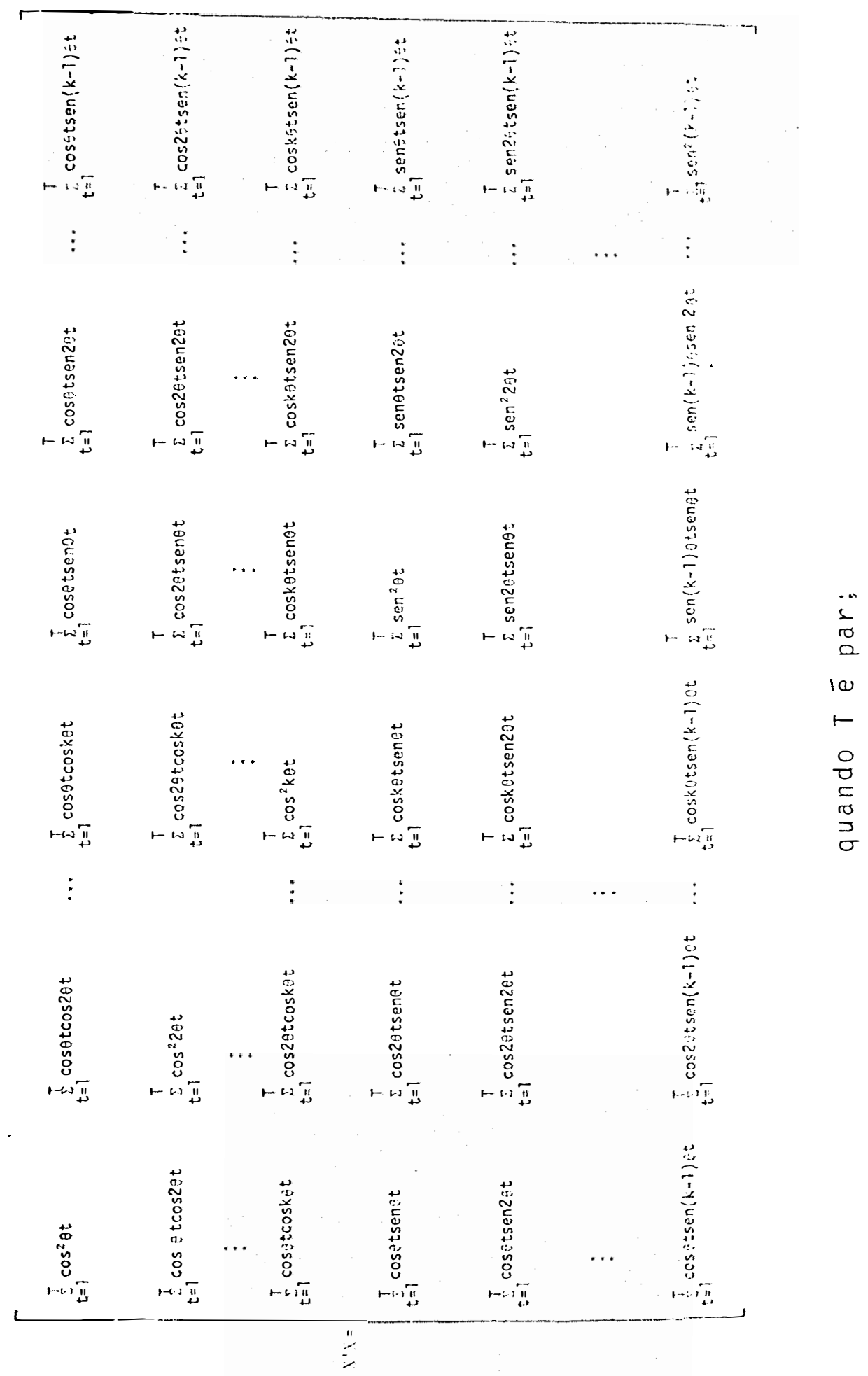




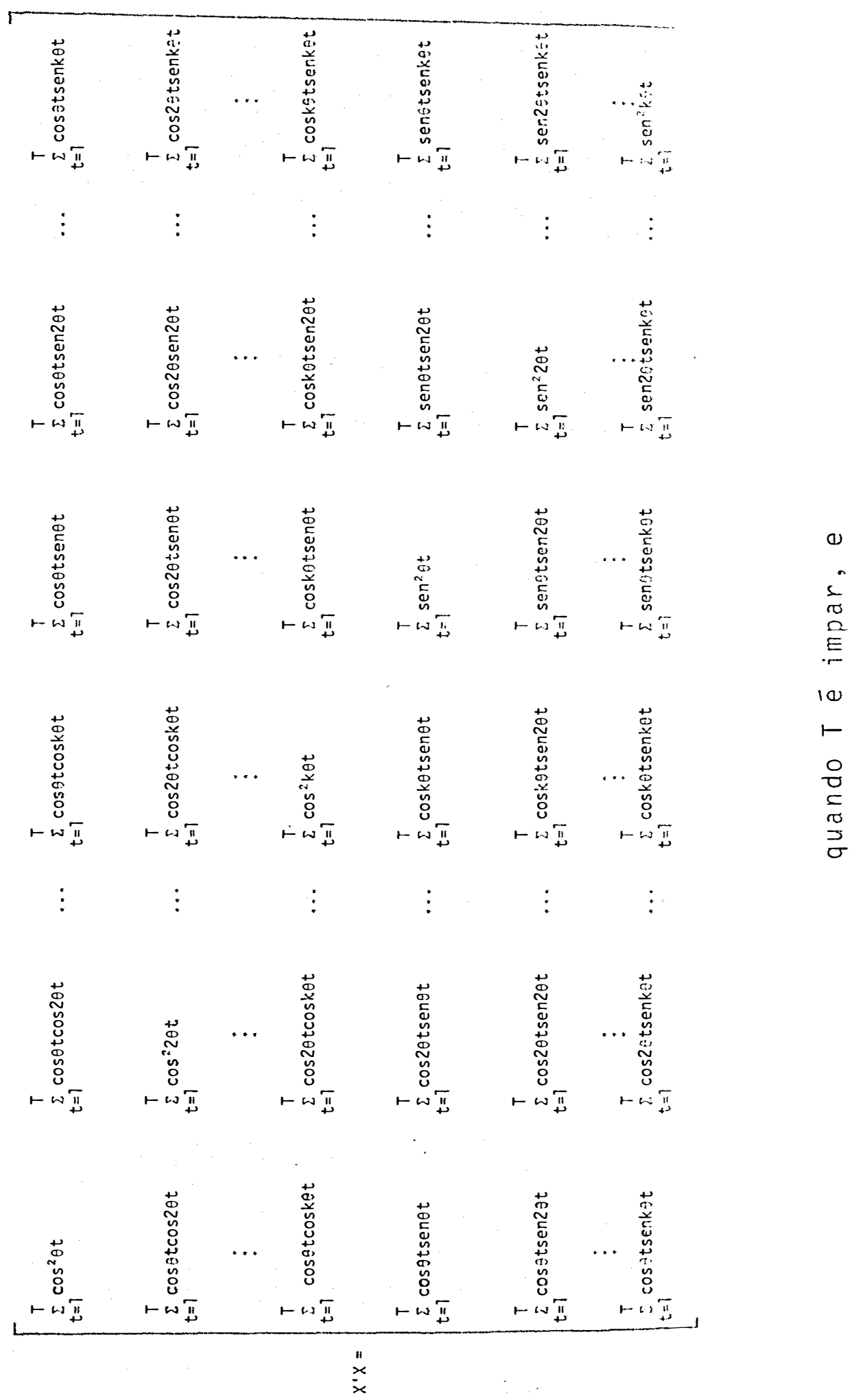


Conforme ANDERSON (1971) atravēs das fórmulas de Euler,

$$
\begin{aligned}
& \cos \theta=\frac{1}{2}\left(e^{i \theta}+e^{-i \theta}\right) ; \\
& \operatorname{sen} \theta=\frac{1}{2 i}\left(e^{i \theta}-e^{-i e}\right) e \\
& e^{i \theta}=\cos \theta+i \operatorname{sen} \theta
\end{aligned}
$$

Comprova-se que:

$$
\begin{aligned}
& \sum_{t=1}^{T} \cos ^{2} j \theta t=\frac{T}{2}, \text { para } j=1,2, \ldots,(k-1), \\
& \sum_{t=1}^{T} \cos ^{2} k \theta t=\frac{T}{2} \quad \text {, quando } T \text { e impar e } \\
& \sum_{t=1}^{T} \cos ^{2} k \theta t=T \text {, quando } T \bar{e} \text { par } \\
& \sum_{t=1}^{T} \operatorname{sen}^{2} j \theta t=\frac{T}{2}, \text { para } j=1,2, \ldots, k
\end{aligned}
$$

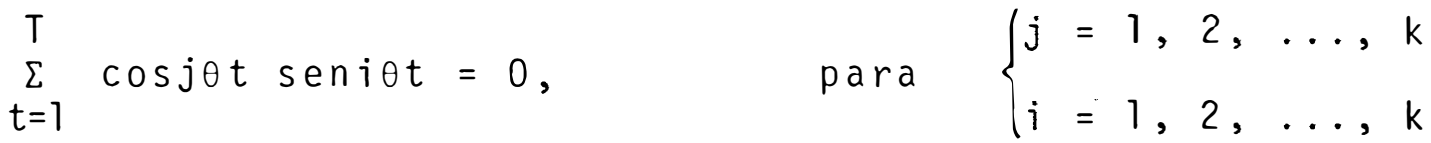

$$
\begin{aligned}
& \sum_{t=1}^{T} \operatorname{cosjet} \cos i \theta t=0, \quad \text { para } j \neq i\left\{\begin{array}{l}
j=1,2, \ldots, k \\
i=1,2, \ldots, k
\end{array}\right. \\
& \sum_{t=1}^{T} \text { senjet seniet }=0, \quad \text { para } j \neq i \quad\left\{\begin{array}{l}
j=1,2, \ldots, k \\
i=1,2, \ldots, k
\end{array}\right.
\end{aligned}
$$


Então a matriz $X^{\prime} X$ pode ser escrita:

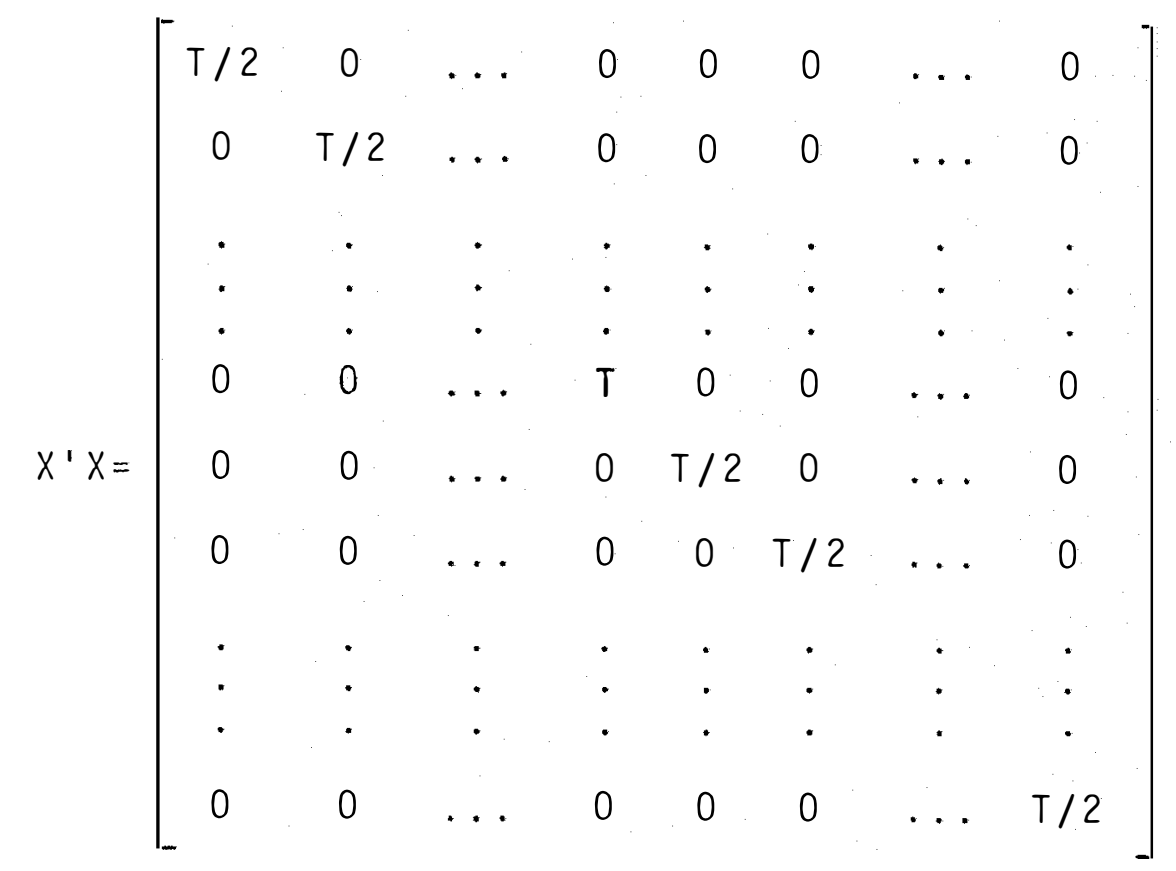

quando T é par, e

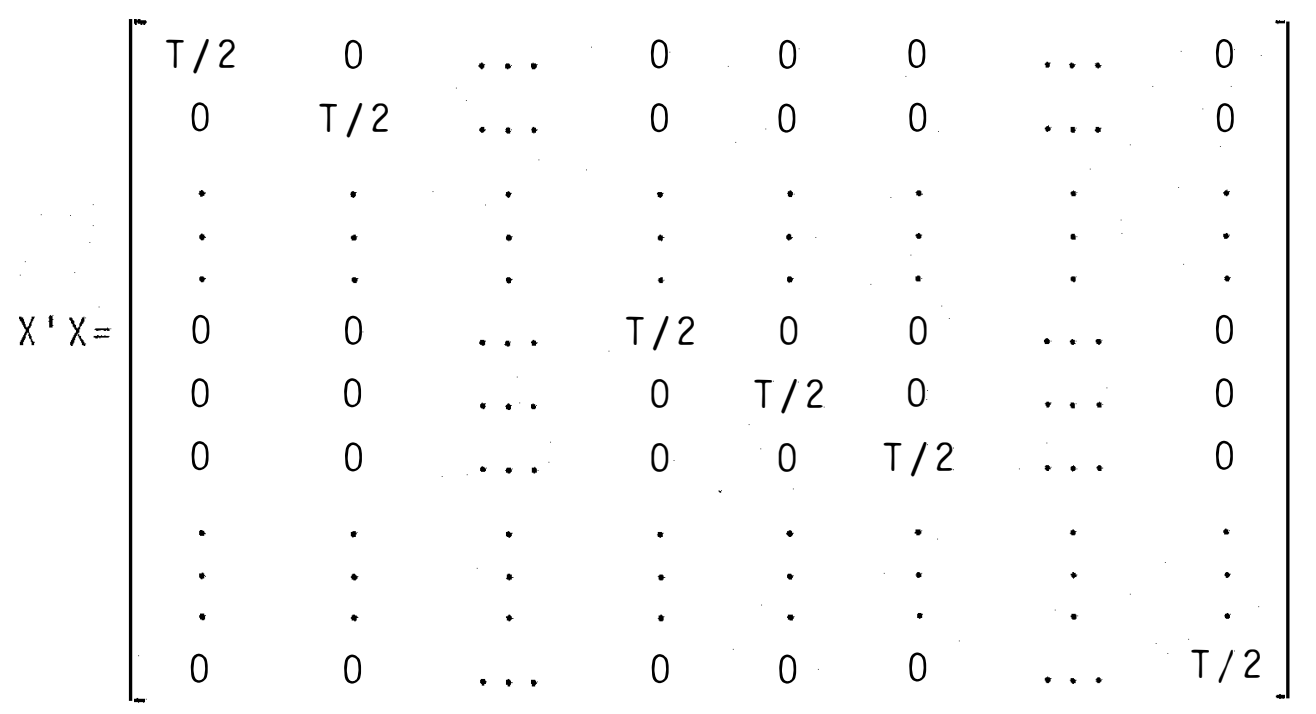

quando T é impar. 


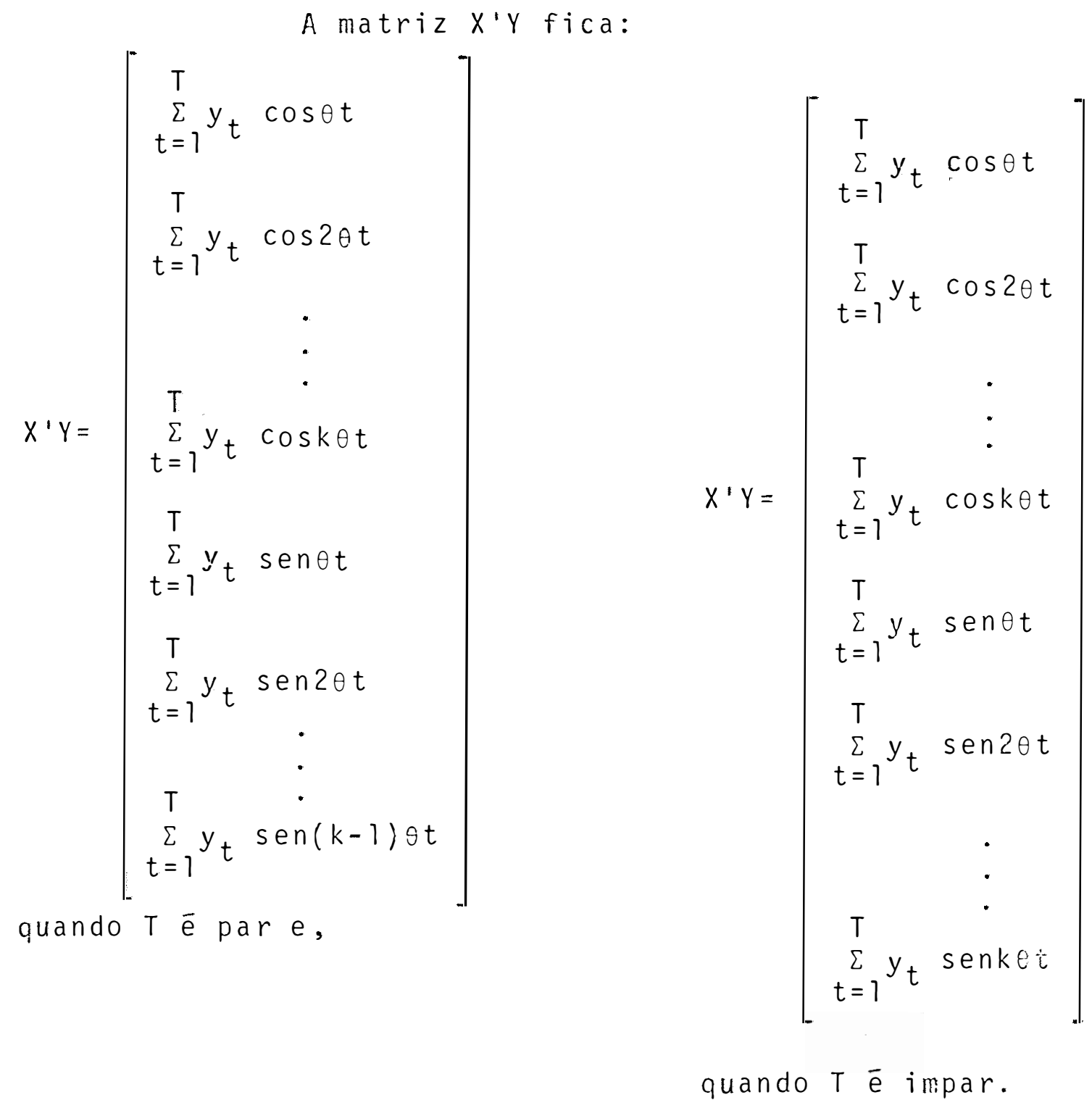

As estimativas dos parāmetros $p_{j}$ e $q_{j}$, atravēs da matriz $\bar{\beta}$, são: 


$$
\begin{aligned}
& \bar{P}_{1}=\frac{2}{T} \sum_{t=1}^{T} y_{t} \cos \theta t \\
& \tilde{P}_{2}=\frac{2}{T} \sum_{t=1}^{T} y_{t} \cos 2 \theta t \\
& \tilde{P}_{k}=\frac{2}{T} \sum_{t=1}^{T} y_{t} \cos k \theta t \text {, quando } T \text { é impar, e } \\
& \bar{P}_{k}=\frac{1}{T} \sum_{t=1}^{T} y_{t} \operatorname{cosket} \text {, quando } T \text { è par. } \\
& \bar{q}_{1}=\frac{2}{T} \sum_{t=1}^{T} y_{t} \operatorname{sen} \theta t \\
& \hat{q}_{2}=\frac{2}{T} \sum_{t=1}^{T} y_{t} \operatorname{sen} 2 \theta t \\
& \bar{q}_{(k-1)}=\frac{2}{T} \sum_{t=1}^{T} y_{t} \operatorname{sen}(k-1) \theta t \\
& \bar{q}_{k}=\frac{2}{T} \sum_{t=1}^{T} y_{t} \operatorname{sen} k \theta t
\end{aligned}
$$

As variāncias e covariāncias dos parāmetros es timados são obtidos na matriz de dispersão $D=\left(X^{\prime} X\right)^{-1} \sigma^{2}$, sen do: 


$$
\begin{aligned}
& V\left(\bar{p}_{j}\right)=2 \sigma^{2} / T \quad \text {, para } j=1,2, \ldots,(k-1) \\
& V\left(\bar{p}_{k}\right)=2 \sigma^{2} / T \text {, quando } T \text { é impar, e } \\
& V\left(\hat{p}_{k}\right)=\sigma^{2} / T \text {, quando } T \text { é par } \\
& V\left(\bar{q}_{j}\right)=2 \sigma^{2} / T \quad \text {, para } j=1,2, \ldots, k
\end{aligned}
$$

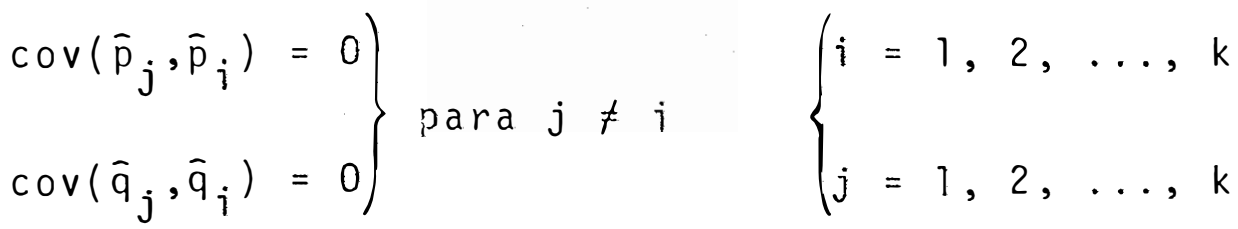

$$
\begin{aligned}
& \operatorname{cov}\left(\bar{p}_{j}, \bar{q}_{j}\right)=0, \quad \text { para } \quad\left\{\begin{array}{l}
i=1,2, \ldots, k \\
j=1,2, \ldots, k
\end{array}\right.
\end{aligned}
$$

pode-se observar que as covariāncias são todas nulas, e com isso conclui-se que os parâmetros estimados são independentes.

Hā interesse em determinar as variāncias das estimativas das amplitudes dos componentes harmōnicos ( $a_{j}$ ). De acordo com FELTRIN (1980), utiliza-se o processo de diferenciação, para a obtenção de seus valores aproximados.

$$
\text { Se } \bar{a}_{j}=\left|\sqrt{\hat{p}_{j}^{2}+\bar{q}_{j}^{2}}\right| \text {, e conhecendo-se as va- }
$$

riâncias e covariāncias de $\bar{p}_{j}$ e $\hat{c}_{j}$, equações (22) a (28),

$$
d\left(\bar{a}_{j}\right)=\frac{\hat{p}_{j}}{\sqrt{\bar{p}_{j}^{2}+\bar{q}_{j}^{2}}} d \bar{p}_{j}+-\frac{\hat{q}_{j}}{\sqrt{\hat{p}_{j}^{2}+\hat{q}_{j}^{2}}} d \bar{q}_{j}
$$




$$
\begin{aligned}
& \left.I d\left(\bar{a}_{j}\right)\right]^{2}=\frac{\hat{p}_{j}^{2}}{\hat{p}_{j}^{2}+\hat{q}_{j}^{2}}\left(d \hat{p}_{j}\right)^{2}+\frac{\hat{q}_{j}^{2}}{\hat{p}_{j}^{2}+\bar{q}_{j}^{2}}\left(d \hat{q}_{j}^{2}\right)+ \\
& +\frac{2 \bar{p}_{j} \overline{\bar{q}}_{j}}{\bar{p}_{j}^{2}+\bar{\tau}_{j}^{2}}\left(d \hat{p}_{j}\right)\left(d \bar{q}_{j}\right) \\
& V\left(\bar{a}_{j}\right)=\frac{\bar{p}_{j}^{2}}{\bar{p}_{j}^{2}+\bar{q}_{j}^{2}} V\left(\hat{p}_{j}\right)+\frac{\bar{q}_{j}^{2}}{\bar{p}_{i}^{2}+\bar{q}_{j}^{2}} V\left(\bar{q}_{j}\right)+\frac{2 \hat{p}_{j} \hat{q}_{j}}{\bar{p}_{j}^{2}+\bar{q}_{j}^{2}} \operatorname{cov}\left(\bar{p}_{j}, \hat{q}_{j}\right),
\end{aligned}
$$

de acordo $\operatorname{com}(28)$, fica:

$V\left(\bar{a}_{j}\right) \simeq \frac{\bar{p}_{j}^{2}}{\bar{p}_{j}^{2}+\bar{r}_{j}^{2}} V\left(\bar{p}_{j}\right)+\frac{\bar{q}_{j}^{2}}{\bar{p}_{j}^{2}+\bar{q}_{j}^{2}} V\left(\bar{q}_{j}\right)$,

pelas equações (22) a (25), tem-se:

$V\left(\bar{p}_{j}\right)=V\left(\bar{q}_{j}\right)=\frac{2 \sigma^{2}}{T}$, para $j=1,2, \ldots,(k-1)$

$V\left(\hat{p}_{k}\right)=V\left(\hat{q}_{k}\right)=\frac{2 \sigma^{2}}{T}$, quando $T \bar{e}$ impare,

$V\left(\hat{p}_{k}\right)=\frac{\sigma^{2}}{T}$, quando $T$ é par.

pela equação (29), chega-se:

$$
V\left(\bar{a}_{j}\right)=\frac{2 \sigma^{2}}{T}, \quad j=1,2, \ldots,(k-1)
$$


$V\left(\hat{a}_{k}\right)=\frac{2 \sigma^{2}}{T}$, quando $T$ é impar, e

$V\left(\bar{a}_{k}\right) \simeq \frac{\sigma^{2}}{T}$, quando $T$ é par

\subsubsection{Transformação dos dados}

Uma das condições bāsicas para a correta aplicação dos testes de significância é que os erros aleatórios tenham distribuição normal.

Quando isso não ocorre, hā necessidade de se fazer a aproximação normal através de transformação dos dados.

Conforme GOMES et alij (1975) as trans formações utilizadas para dados pluviométricos a fim de se ob ter uma distribuição aproximadamente normal, têm sido encontradas frequentemente por processos de tentativas ou baseados em informações de literatura referentes a trabalhos efetuados em outros locais. Uma transformação muito usada para dados pluviométricos é a logaritma, expressa pelo logarît:io natural ou decimal dos dados quando não ocorrem zeros, ou, caso contrário, pelo logarítmo dos dados acrescidos de uma constante. Neste caso a escolha do valor da constante fica depen dendo de posterior verificação de seu ajustamento aos dados para que a transformação seja considerada satisfatória. 
AMARAL e MOTA (1956) citados por GOdOY et alii (1961) sugerem uma transformação do tipo $y=\log (x+b / a)$, onde a e b são os coeficientes da equação de regressão linear do tipo $\sigma_{x}=a x+b$, onde $\sigma_{x} \bar{e}$ o desvio padrão relativo aos meses considerados e $x \bar{e}$ a média das precipitações mensais. AMARAL (1968) desaconselha o uso da transforma ção $\sigma_{x}=a x+b$, pois the parece que para dados de precipitações mensais o desvio padrão não seja função linear da média, parecendo-lhe preferível exprimir o desvio padrão na forma,

$$
\sigma_{x}=\beta x^{a}
$$

onde os valores a e $\beta$ podem ser determinados para cada grupo de observações, sendo x a média de precipitação mensal num pe ríodo de $N$ anos e $\sigma_{x}$ o desvio padrão das observações utiliza das para o cálculo desta média. Determinado o valor de "a"sugere a transformaça do tipo,

$$
z=x^{(2-a)}
$$

Silva (1977) citado por FELTRIN (1980) sugere a padronização da transformação para dados pluviométricos, atrá vēs da fórmula:

$$
y=\sqrt[3]{x}
$$

No presente trabalho, utilizando-se a trans- 
formação do tipo $z=x^{(1-a)}$ para uma sērie de 47 anos obte ve-se $z=x^{(0,325)}$.

\subsubsection{Anālise da variància}

Para testar a estabilidade dos componentes harmônicos foi usada a anālise de variāncia.

\subsubsection{Teste de normalidade}

Visando uma aplicação mais correta do teste $F$, usou-se o critério de Fischer de 1941, citado por AMARAL (1968), aos contrastes $\hat{p}_{k}$ e $\bar{q}_{k}$ da regressão periódica. De acordo com o autor o critério de Fischer consiste em testar os coeficien tes de assimetria e curtose de uma amostra para verificar sua aproximação à normalidade. No presente trabalho a amostra é constituída pelo conjunto de contrastes $\bar{p}_{k}$ e $\bar{q}_{k}$, que se encon tram no apêndice 7.

AMARAL (1968) afirma que quando se dispōe de dados de um nümero suficientemente grande de anos, o melhor teste de normalidade consiste em comparar as medidas de assimetria $\left(g_{1}\right)$ e curtose $\left(g_{2}\right)$ dos contrastes, com as respecti- 
vas medidas de assimetria $\left(g_{1}=0\right)$ e curtose $\left(g_{2}=0\right)$ da distribuição normal através do teste $t$.

As fórmulas usadas para o cálculo das estimativas de assimetriae curtose são dadas a seguir:

Coeficiente de assimetria:

$$
g_{1}=\frac{k_{3}}{\sqrt{k_{2}^{3}}}
$$

Coeficiente de curtose:

$$
g_{2}=\frac{k_{4}}{k_{2}^{2}}
$$

onde por exemplo, para o contraste $\hat{p}_{1}$, tem-se:

$$
k_{2}=\frac{\sum_{i=1}^{N}\left(\hat{p}_{1 i}-\bar{p}_{1}\right)^{2}}{N-1}
$$

$k_{3}=\frac{N \sum_{i=1}^{N}\left(\bar{p}_{1 i}-\bar{p}_{1} j^{3}\right.}{(N-1)(N-2)}$

$$
k_{4}=\frac{N}{(N-1)(N-2)(N-3)}\left\{(N+1) \sum_{i=1}^{N}\left(\bar{p}_{1} i^{-\bar{p}_{1}}\right)^{4}-3 \frac{\|-1}{i}\left[\sum_{i=1}^{N}\left(\bar{p}_{1} i^{-\bar{p}_{1}}\right)^{2}\right]^{2}\right\}(37)
$$


Segundo o autor, para grandes amostras $g_{1}$ e $g_{2}$ distribuem-se normalmente com médias iguais a zero e desvios padrão dados por:

$$
\begin{aligned}
& s\left(\hat{g}_{1}\right)=\sqrt{\frac{6 N(N-1)}{(N-2)(N+1)(N+3)}} \\
& s\left(\hat{g}_{2}\right)=\sqrt{\frac{24 N(N-1)^{2}}{(N-3)(N-2)(N+3)(N+5)}}
\end{aligned}
$$

As hipótese a ser testadas são:
$H_{0}: g_{1}=0$
$H_{0}: g_{2}=0$
$H_{1}: g_{1} \neq 0$
$H_{1}: g_{2} \neq 0$

Essas hipóteses são testadas através do teste t, a um nivel a de probabilidade, com N-l graus de liberdade. Assim tem-se:

$$
\begin{aligned}
& t_{1}=\frac{\hat{g}_{1}-0}{s\left(\hat{g}_{1}\right)} \\
& t_{2}=\frac{\bar{g}_{2}-0}{s\left(\hat{g}_{2}\right)} .
\end{aligned}
$$


3.2.5.2. Quadros de anālise de variância

De acordo com BLISS (1958), AMARAL (1968), PEREIRA (1978) e FELTRIN (1980), a anālise para este caso, assemelha-se ao modelo empregado para blocos ao acaso. Assim, para cada componente harmōnico será usado, uma variāncia residual (interação anos $x$ componentes harmōnicos), relativa a variação apresentada no decorrer dos anos. Os quadros de variância são dados a seguir: 
Tabela 1 - Anālise de variância dos contrastes $\bar{p}_{j}$ e $\bar{q}_{j}$, para o caso de $T$ impar.

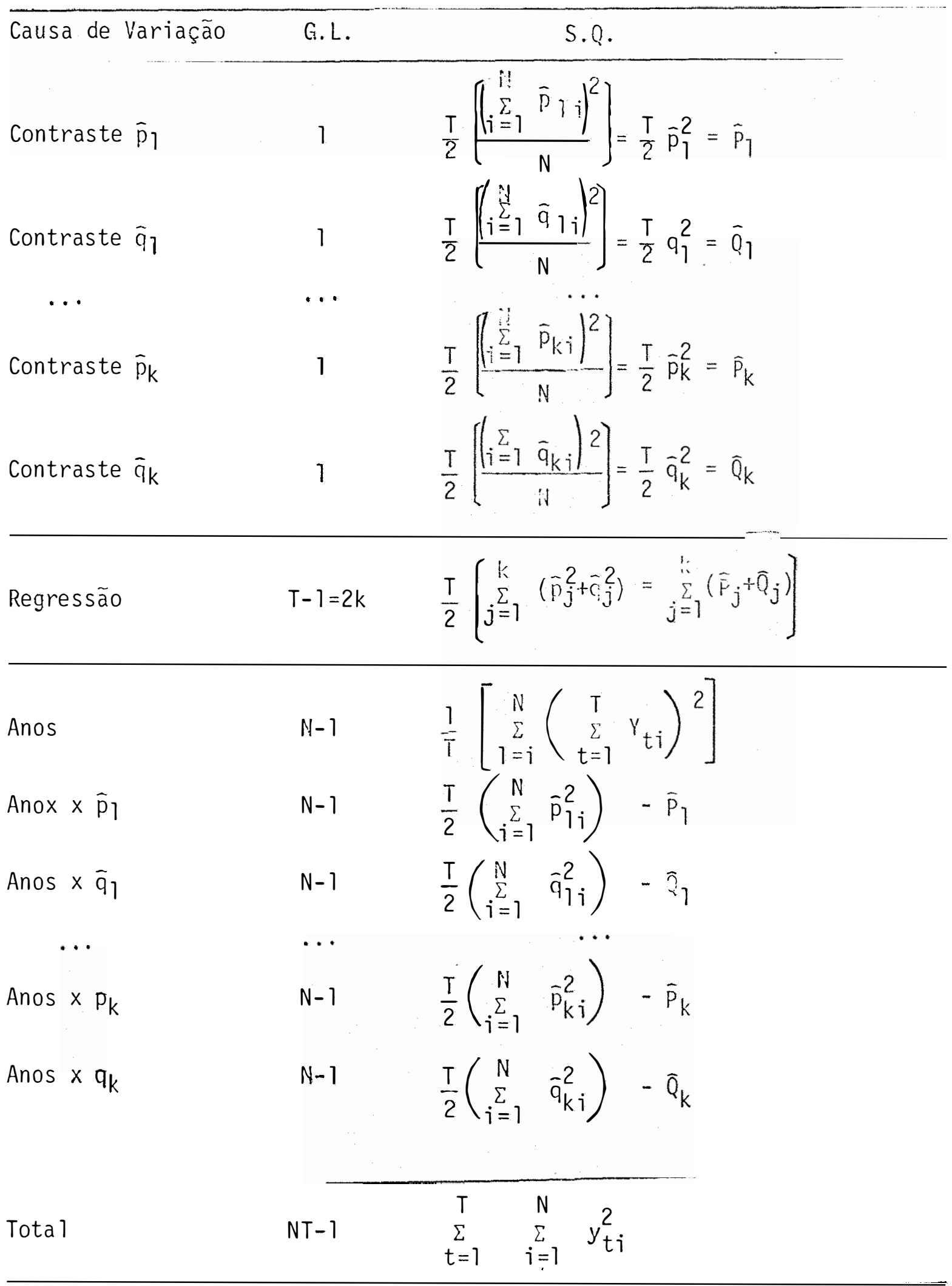


Tabela 2 - Anālise de variāncia dos contastes $\bar{p}_{j}$ e $\bar{q}_{j}$, para o caso de $T$
par. Causa de Variação G.L. S.Q.

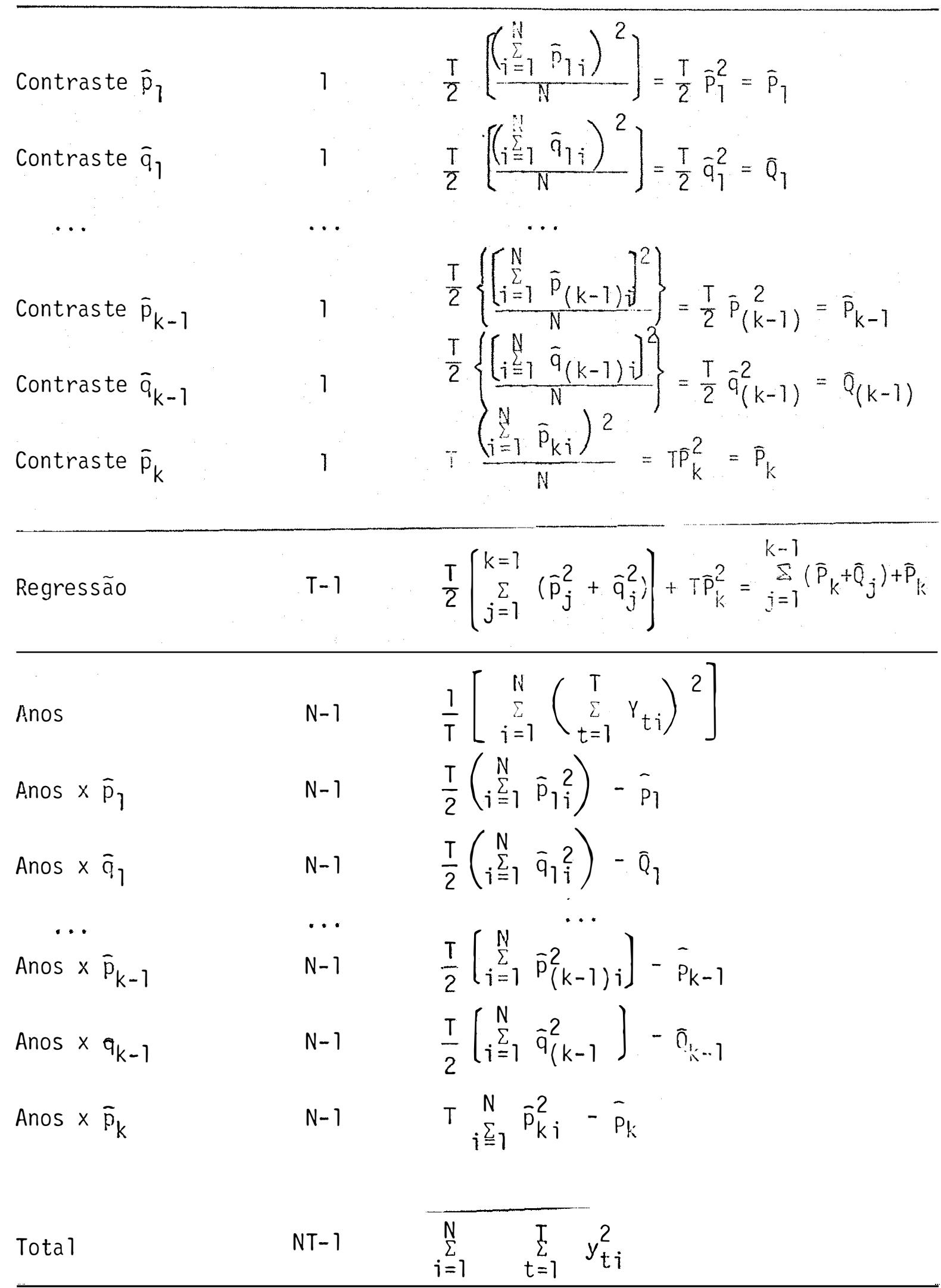


Conforme AMARAL (1968) deve-se aplicar a anälise de variância, não apenas aos contrastes, mas tambēm à cada amplitude dos componentes harmónicos, desde que as variāncias referentes aos contrastes $\bar{p}_{j}$ e $\bar{q}_{j}$ sejam homogêneas e que $\bar{p}_{j}^{2}+\hat{q}_{j}^{2}=\hat{a}_{j}^{2}$, pode-se juntá-las para obter o teste de significância da amplitude correspondente, conforme esquemas de anālises de variãncia a seguir. 

Tabela 3 - Anālise de variância das amplitudes $\bar{a}_{j}$, para o caso de T ím-
par.

Causa de Variação

G.L.

S.Q.

Amplitude $\hat{a}_{1}$

$2 \quad \bar{P}_{1}+\bar{Q}_{1}$

Ampritude $\bar{a}_{2}$

$2 \quad \bar{P}_{2}+\bar{Q}_{2}$

Amplitude $\hat{a}_{k}$

$2 \quad \bar{p}_{k}+\widehat{0}_{k}$

Regressão $\quad T-1=2 k \quad \sum_{j=1}^{k}\left(\bar{P}_{j}+\bar{Q}_{j}\right)$

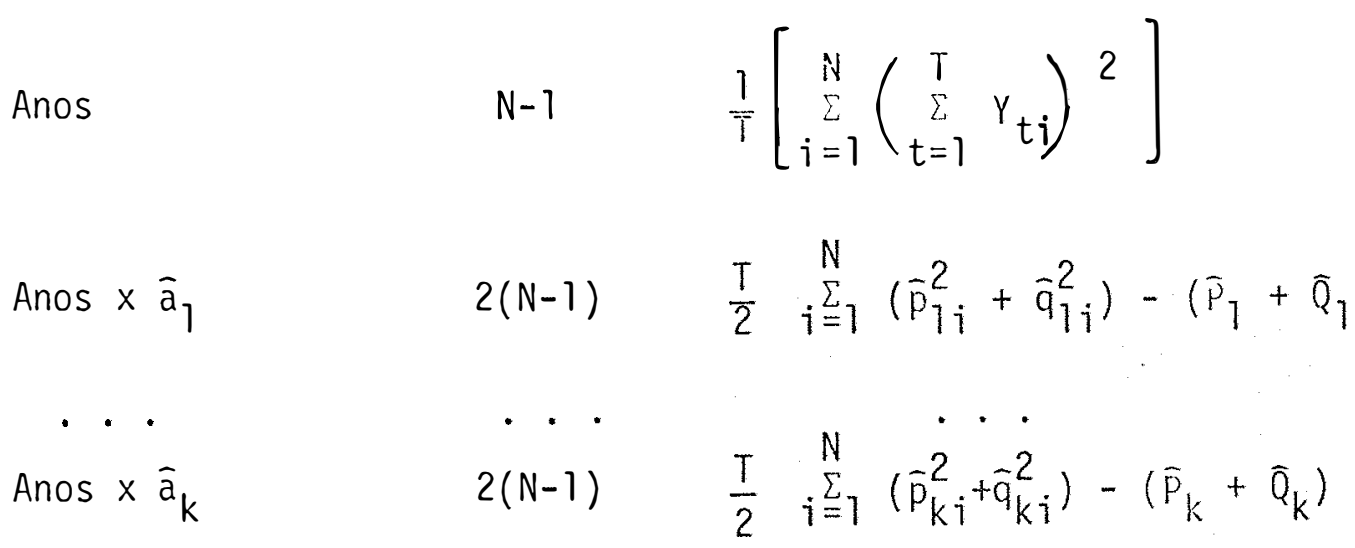

Total

NT-1

$\underset{i=1}{N} \quad \sum_{t=1}^{T} y_{t i}^{2}$ 
Tabela 4 - Anālise de variāncia das amplitudes $\bar{a}_{j}$, para o caso de T par.

Causa de Variação

G.L.

S.Q.

Amplitude $\bar{a}_{1}$

$2 \quad \bar{p}_{1}+\bar{Q}_{1}$

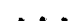

Amplitude $\bar{a}(k-1)$

$2 \quad \tilde{P}_{(k-1)}+\hat{Q}_{(k-1)}$

Amplitude $\bar{a}_{k}$

$1 \quad \widehat{P}_{k}$

Regressão

$T-1 \quad\left[\sum_{j=1}^{k-1}\left(\bar{P}_{j}+\bar{Q}_{j}\right)\right)+\hat{P}_{k}$

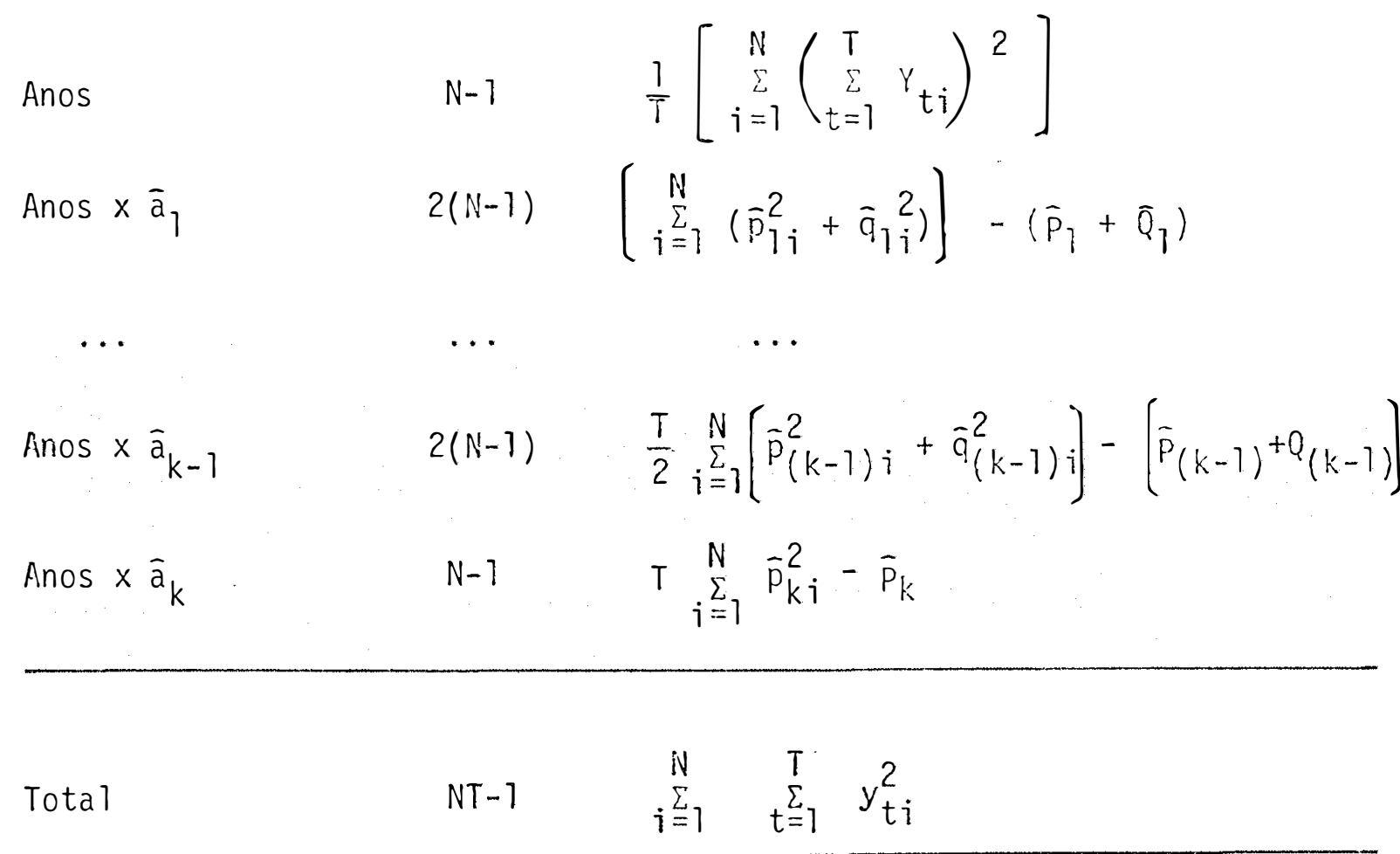


3.2.6. Intervalo de confiança para os parâmetros estimados

Tendo-se obtido as estimativas $\bar{p}_{j}, \bar{q}_{j}$ e $\bar{a}_{j}$, e os quadrados médios das suas respectivas interações com anos, pode-se determinar os intervalos de confiança para os parâmetros.

$$
\begin{array}{r}
\text { Para } p_{j} \text { e } q_{j} \text {, tem-se: } \\
\hat{p}_{j}-t \cdot s\left(\hat{p}_{j}\right) \leq p_{j} \leq \hat{p}_{j}+t \cdot s\left(\hat{p}_{j}\right) \\
\hat{q}_{j}-t \cdot s\left(\bar{q}_{j}\right) \leq q_{j} \leq \bar{q}_{j}+t \cdot s\left(\hat{q}_{j}\right)
\end{array}
$$

sendo t obtido na tabela de $t$, bilateral com $N-l$ graus de 1 iberdade; a um nîvel a de significāncia.

$$
\begin{gathered}
\operatorname{Para}_{j}, \\
\bar{a}_{j}-t \cdot s\left(\bar{a}_{j}\right) \leq a_{j} \leq \bar{a}_{j}+t \cdot s\left(\bar{a}_{j}\right)
\end{gathered}
$$

sendo t obtido na tabela de $t$, bilateral com $2(N-1)$ graus de liberdade, exceto no caso de $a_{k}$ para $T$ par; nesse caso o número de graus de liberdade é $\mathbb{N}-1$, a um determinadonível a de significāncia.

\subsubsection{Equação de regressão}

Selecionados os componentes hormōnicos signifi cativos, através da anālise de variāncia, pode-se estabelecer 
a equação de regressão para os dados observados.

No entanto, foram considerados os componentes harmōnicos, atē o ūtimo significativo.

Fez-se, ainda a representação grāfica de cada componente harmōnico, bem como da sintese de todas as ondas significativas. 
40.

\section{IESULTADOS E DISCUSSÃO}

Para a metodologia descrita procurou-se estimar as precipitações mensais para o período anual, de janeiro a dezembro.

Os dados originais de precipitação mensais, em milímetros, são encontrados no apêndice 1 , e após o ajuste pa ra mês de 30 dias, visando a uma homogeneização das variānciais, foi efetuada a transformação $x^{0,325}$, conforme 3.2.4.

\subsection{Estimativa das Precipitações Mensais para O Periodo Anual (janeiro a dezembro)}

Para o período estudado calculou-se à média dos 564 dados, após a transformação $x^{0}, 325$ obtendo - se valor 3,8348. Em seguida, obteve-se os desvios dos dados em relação à média, cujos resultados são apresentados no apêndice 4. 
o periodo anual pode ser dividido em seis ondas senoidais com períodos minimos de $12,6,4,3,12 / 5$, e 2 meses, respectivamente, com as frequéncias $\frac{1}{12}, \frac{1}{6}, \frac{1}{4}, \frac{1}{3}, \frac{5}{12}$ e $\frac{1}{2}$.

\subsubsection{Modêlo matemático}

Para o periodo anual, ou seja, para $T=12,0$ modēlo matemático de acordo com (21) em 3.2.2. é o seguinte:

$$
\begin{aligned}
y_{t}=p_{1} \cos \theta t & +p_{2} \cos 2 \theta t+p_{3} \cos 3 \theta t+ \\
& +p_{4} \cos 4 \theta t+p_{5} \cos 5 \theta t+ \\
& +p_{6} \cos 6 \theta t+q_{1} \operatorname{sen} \theta t+ \\
& +q_{2} \operatorname{sen} 2 \theta t+q_{3} \operatorname{sen} 3 \theta t+ \\
& +q_{4} \operatorname{sen} 4 \theta t+q_{5} \operatorname{sen} 5 \theta t+e_{t}
\end{aligned}
$$

considerando-se $\theta$ em graus, tem-se:

$$
\begin{aligned}
& \theta=\frac{3600}{12}=300 \\
& t=1,2, \ldots, 12 .
\end{aligned}
$$

Como para cada mês têm-se 47 repetições, correspondentes aos 47 anos no periodo estudado o modelo fica:

$$
\begin{aligned}
y_{t i}=p_{1 i} \cos \theta t & +p_{2 i} \cos 2 \theta t+p_{3 i} \cos 3 \theta t+ \\
& +p_{4 i} \cos 4 \theta t+p_{5 i} \cos 5 \theta t+ \\
& +p_{6 i} \cos 6 \theta t+q_{1 i} \operatorname{sen} \theta t+ \\
& +q_{2 i} \operatorname{sen} 2 \theta t+q_{3 i} \operatorname{sen} 3 \theta t+ \\
& +q_{4 i} \operatorname{sen} 4 \theta t+q_{5 i} \operatorname{sen} 5 \theta t+e_{t i}
\end{aligned}
$$


Pode-se observar que a matriz Y terá dimensões $T \times N$, ou seja, $12 \times 47$, sendo encontrada no apéndice 4, na forma $Y^{\prime}$.

\subsubsection{Estimativa dos parāmetros}

De acordo com a metodologia exposta em 3.2.3., a solução do sistema de equações, calculado com auxilio do computador, apresentou os seguintes valores médios para os pa rāmetros referentes ao périodo de 47 anos:

$$
\begin{aligned}
& \hat{p}_{1}=-1,33157 \\
& \hat{p}_{2}=-0,00798 \\
& \hat{p}_{3}=0,07966 \\
& \vec{p}_{4}=0,07515 \\
& \vec{p}_{5}=-0,04925 \\
& \hat{p}_{6}=-0,03486
\end{aligned}
$$

$$
\begin{aligned}
& \hat{q}_{1}=0,69801 \\
& \hat{q}_{2}=0,25925 \\
& \hat{q}_{3}=-0,03857 \\
& \hat{q}_{4}=-0,03003 \\
& \hat{q}_{5}=0,02370
\end{aligned}
$$

A partir desses valores pode-se determinar os valores das amplitudes correspondentes aos contrastes $\bar{p}_{j}$ e $\hat{q}_{j}$, desde que:

$$
\begin{aligned}
& \hat{a}_{j}=\left|\sqrt{\bar{p}_{j}^{2}+\bar{q}_{j}^{2}}\right| \text { e tambēm, } \\
& \operatorname{tg} \widehat{A}_{j}=\frac{\bar{p}_{j}}{\bar{q}_{j}} \text {. Onde } \bar{A}_{j}=\operatorname{arctg}\left(\frac{\widehat{p}_{j}}{\bar{q}_{j}}\right) \text {, desta forma; }
\end{aligned}
$$

tem-se: 


$$
\begin{array}{ll}
\overline{\mathrm{a}}_{1}=1,5034 & \overline{\mathrm{a}}_{4}=0,08092 \\
\overline{\mathrm{a}}_{2}=0,2593 & \overline{\mathrm{a}}_{5}=0,05465 \\
\hat{\mathrm{a}}_{3}=0,0885 & \overline{\mathrm{a}}_{6}=0,03486
\end{array}
$$

e os respectivos àngulos fases:

$$
\begin{array}{ll}
\widehat{A}_{1}=297,66350 & \widehat{A}_{4}=111,78160 \\
\widehat{A}_{2}=358,23690 & \widehat{A}_{5}=295,69770 \\
\widehat{A}_{3}=115,83540 & \widehat{A}_{6}=270 \varphi
\end{array}
$$

Os apēndices 5,6 e 7 apresentam respectivamen te, as matrizes $X,\left(X^{\prime} X\right)^{-1}$ e $\bar{\beta}^{\prime}$.

4.1.3. Anālise de variāncia

\subsubsection{Teste de normalidade}

Visando atender às exigèncias do teste $F$, foi aplicado um teste de normalidade aos contrastes $\bar{p}_{j}$ e $\bar{q}_{j}$ obtidos para os 47 anos, conforme descrito em 3.2.5.1. Os cálculos foram obtidos pelo computador, e são apresentados na tabela 5.

Os desvios padrão de $\hat{g}_{1}$ e $\hat{g}_{2}$, para aplicação do "teste $t$ " apresentaram os seguintes valores:

$$
\begin{aligned}
& s\left(\bar{g}_{1}\right)=0,3465, \\
& s\left(\bar{g}_{2}\right)=0,6809
\end{aligned}
$$


Tabela 5 - Valores dos coeficientes de assimetria $\left(g_{1}\right)$ e curtose $\left(g_{2}\right)$ e os respectivos valores cie $t$ calculados para os contrastes $\hat{p}_{j}$ e $\hat{q}_{j}$, de interesse.

\begin{tabular}{ccccc}
\hline Contraste & $\bar{g}_{1}$ & $\bar{g}_{2}$ & $t_{1}$ & $t_{2}$ \\
\hline $\bar{p}_{1}$ & 0,6164 & 0,3737 & 1,7789 & 0,5488 \\
$\hat{q}_{1}$ & 0,6909 & 0,0965 & 1,9939 & 0,1417 \\
$\hat{p}_{2}$ & 0,5124 & 1,2961 & 1,4787 & 1,9035 \\
$\hat{q}_{2}$ & 0,0434 & $-1,0326$ & 0,1252 & $-1,5165$ \\
\hline
\end{tabular}

os valores de $t$ calculados, mostraram-se não significativos, e assim pode-se aceitar que os contrastes lineares são normalmente distribuídos.

4.1.3.2. Ouadros de anālise de variància

A tabela 6 apresenta os resultados obtidos na anāilise de variāncia aplicada aos contrastes $\hat{p}_{j}$ e $\bar{q}_{j}$, até 0 segundo harmônico.

Observa-se pelo teste $F$, que houve significāncia para os contrastes referentes às ondas: anual e semestral. 
Tabela 6 - Anālise de variāncia referente aos contrastes $\bar{p}_{j}$ e $\bar{q}_{j}$ das precipitações mensais em Bananeiras - (PB), isolando apenas os contrastes referentes aos compo nentes harmōnicos, que farão parte da equação de regressão.

\begin{tabular}{lrrrr}
\hline causa de variação & gl & SQ & QM & $F$ \\
\hline contraste $\bar{p}_{1}$ & 1 & & 500,0118 & $241,48 *$ \\
contraste $\bar{q}_{1}$ & 1 & & 137,3970 & $79,39 * \star$ \\
contraste $\bar{p}_{2}$ & 1 & & 0,0179 & 0,01 \\
contraste $\bar{q}_{2}$ & 1 & & 18,9537 & $13,52 * \star$ \\
Desvios de Regressão & 7 & 5,5846 & 0,7978 & 0,74 \\
\hline Anos & 46 & 144,5044 & 3,1414 & \\
Anos $\times \bar{p}_{1}$ & 46 & 95,2495 & 2,0706 & \\
Anos $\times \bar{q}_{1}$ & 46 & 79,6078 & 1,7306 & \\
Anos $\times \bar{p}_{2}$ & 46 & 83,2566 & 1,8099 & \\
Anos $\times \bar{q}_{2}$ & 46 & 64,4739 & 1,4016 & \\
Anos $\times$ Desvios & 322 & 347,0841 & 1,0779 & \\
& & & & \\
\hline
\end{tabular}

Conforme AMARAL (1968) se as variāncias referentes aos contrastes $\bar{p}_{j}$ e $\bar{q}_{j}$ forem homogēneas e, desde que $\hat{a}_{j}^{2}=\bar{p}_{j}^{2}+\bar{q}_{j}^{2}$, pode-se juntā-las para obter o teste de signifi 
46.

cância para a amplitude correspondente, conforme esquema a seguir:

Tabela 7 - Anālise de variāncia referente às amplitudes $\bar{a}_{j}$ das precipitações mensais em Bananeiras (PB), isolando apenas os componentes harmōnicos que farão parte da equação de regressão.

\begin{tabular}{lrrrr}
\hline Causa de Variação & gl & SQ & QM & $F$ \\
\hline Amplitude $\hat{a}_{1}$ & 2 & 637,4088 & 318,7044 & $167,68 * *$ \\
Amplitude ầ & 2 & 18,9716 & 9,4858 & $5,90 * *$ \\
Desvios de regressão & 7 & 5,5846 & 0,7978 & 0,79 \\
\hline Anos & & & & \\
Anos $\times \hat{a}_{1}$ & 46 & 144,5044 & 3,1414 & \\
Anos $\times \hat{a}_{2}$ & 92 & 174,8574 & 1,9006 & \\
Anos $\times$ Desvios & 92 & 147,7304 & 1,6057 & \\
\end{tabular}

Total

5631476,1413

Pelos resultados obtidos pode-se verificar pe10 "teste $F^{\prime \prime}$ que foram significativas as ondas anual e semestral sendo que o anual é responsāvel por 96,29\% das variações pluviométricas no municipio de Bananeiras-PB, e a onda semestral apenas 2,86\%. 
De acordo com AMARAL (1975) em um clima tropical continental com regime de chuvas convectivas e seca de in verno, quase toda a variação das precipitações pluviais ao longo do ano corre à conta da onda anual.

\subsubsection{Variāncias dos parāmetros estimados}

De acordo com 3.2.3. equações (22) a (28), foram estimadas as variāncias dos contrastes $\bar{p}_{j}$ e $\bar{q}_{j}$, e das amplitudes $\bar{a}_{j}$, comforme (29), para os componentes harmónicos considerados na equação de regressão:

$$
\begin{array}{ll}
\bar{V}\left(\bar{p}_{1}\right)=0,3451 & \bar{V}\left(\bar{q}_{1}\right)=0,2884 \\
\bar{V}\left(\bar{p}_{2}\right)=0,3016 & \bar{V}\left(\bar{q}_{2}\right)=0,2336 \\
\bar{V}\left(\bar{a}_{1}\right)=0,3167 & \\
\bar{V}\left(\bar{a}_{2}\right)=0,2676 &
\end{array}
$$

As covariāncias $\bar{p}_{j}$ e $\bar{q}_{j}$ são todas nulas, indicando então que os parâmetros não são correlacionados.

\subsubsection{Intervalos de confiança}

Tendo-se obtido as estimativas $\hat{p}_{j}, \bar{q}_{j}$ e $\hat{a}_{j}$, e suas variāncias, calculou-se os seus respectivos intervalos de confiança, com o t tabelado obtido de 46 graus de liberdade e um $\alpha=0,05$, conforme tabela a seguir: 
Tabela 8 - Intervalos de confiança para os parāmetros $\bar{p}_{j}, \hat{q}_{j}$ e $\tilde{a}_{j}$, que farão parte da equação de regressão.

$\begin{aligned} &-2,5123 \leq p_{1} \leq-0,1507 \\ &-0,3814 \leq q_{1} \leq 1,7774 \\ & 0,3857 \leq a_{1} \leq 2,6210 \\ &-1,1118 \leq p_{2} \leq 1,0958 \\ &-0,7122 \leq q_{2} \leq 1,2307 \\ &-0,7680 \leq a_{2} \leq 1,2866\end{aligned}$

4.1.6. Equação de regressão

A partir das ondas significativas, foi estabelecida a equação de regressão para estimar as precipitações mensais em milimetros para o municipio de Bananeira (PB).

$$
\bar{y}_{t}=3,8348+1,5034 \operatorname{sen}(30 t+297,6635)^{\circ}+0,2593 \operatorname{sen}(60 t+358,2369)^{\circ}
$$

onde:

$$
\begin{aligned}
\hat{y}_{t}= & \text { estimativa da poténcia } x^{0,325} \text { do valor observado para } \\
& 0 \text { mês } t .
\end{aligned}
$$

A equação de regressão acima explica $99,15 \%$ da variação das precipitações pluviais mensais no município de Bananeira - PB .

A Tabela 9 contēm os resultados das estimativas dapotência $x^{0,325}$, obtidas atravēs da equação de regressão: 


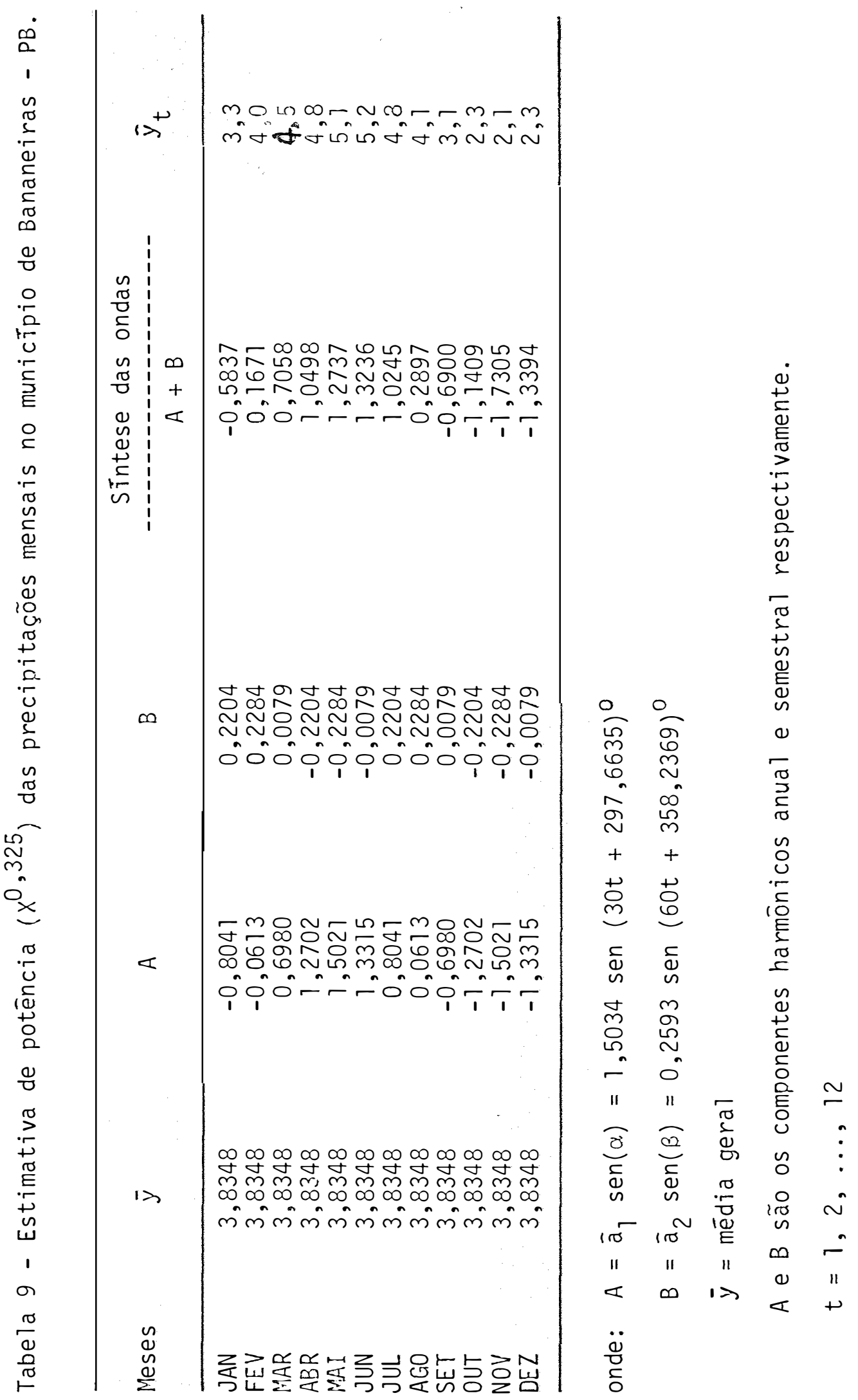


4.1.7. Representação grāfica

Com os resultados obtidos na tabela 9 , construiu-se os gráficos das ondas significativas, de cada componente harmōnico considerado na equação de regressão e da sintese das duas ondas, sendo apresentados nas figuras 1, 2 e 3 .

A figura 4 , representa a equação de regressão, obtida à partir dos valores estimados. 


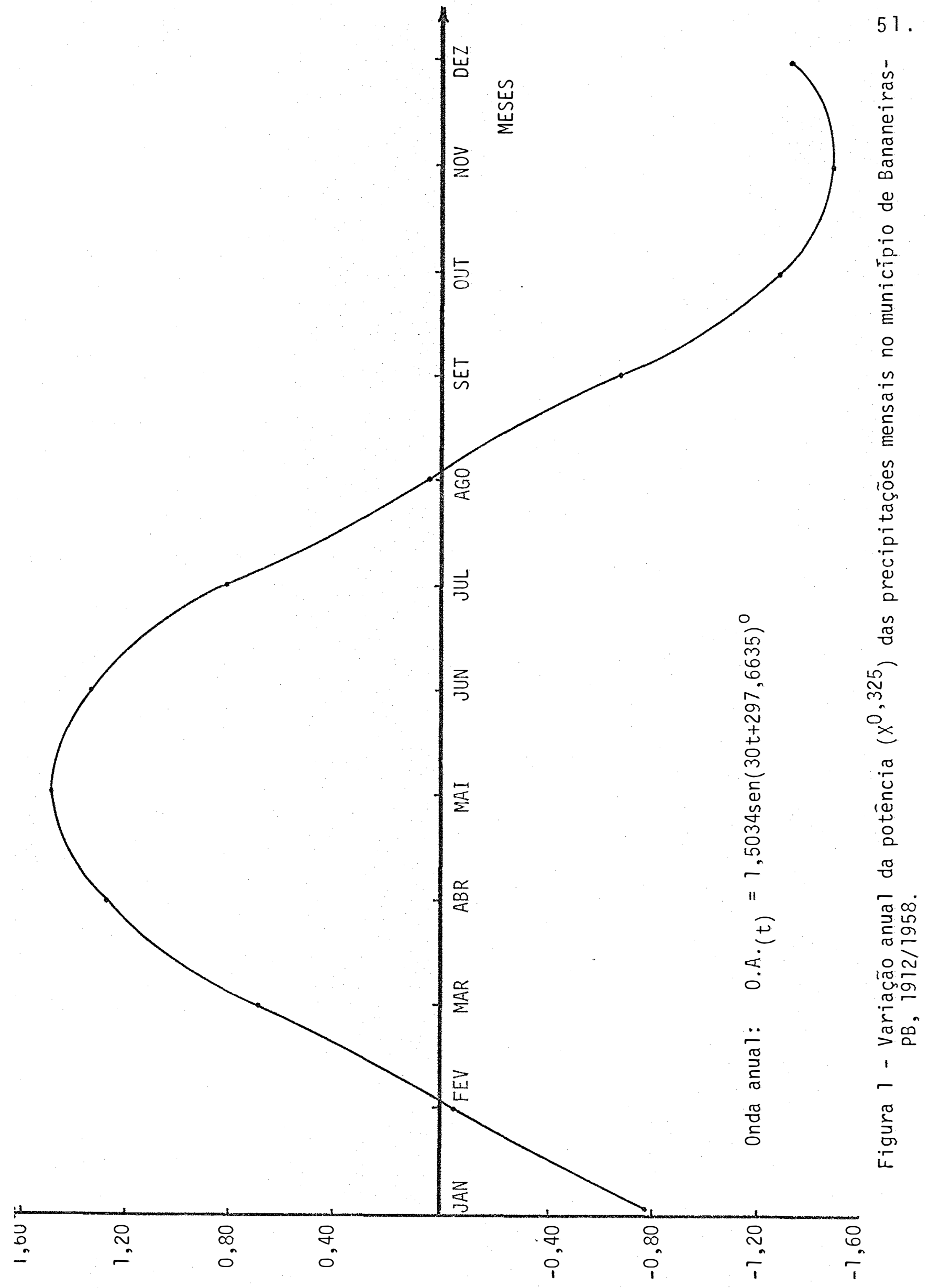




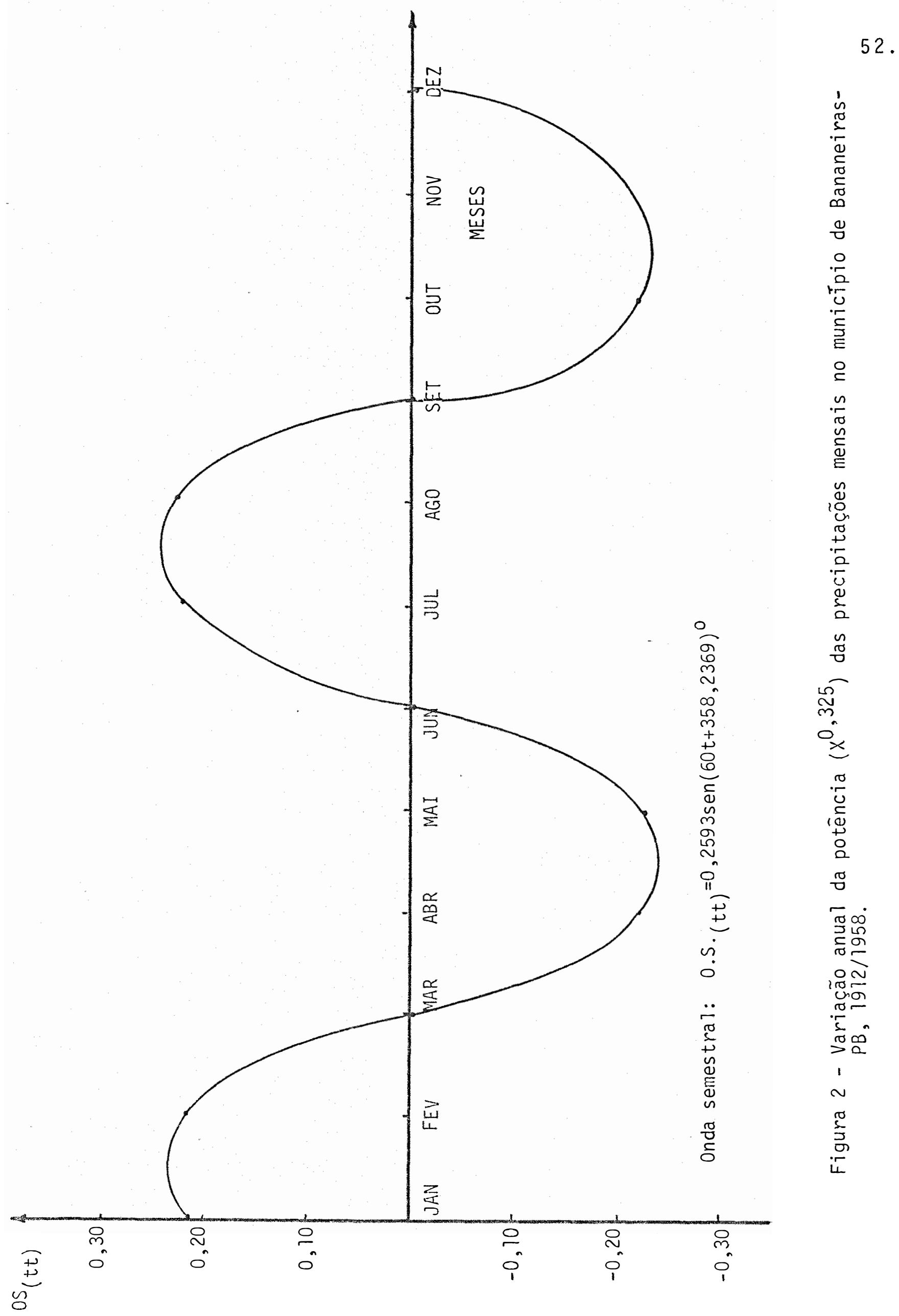




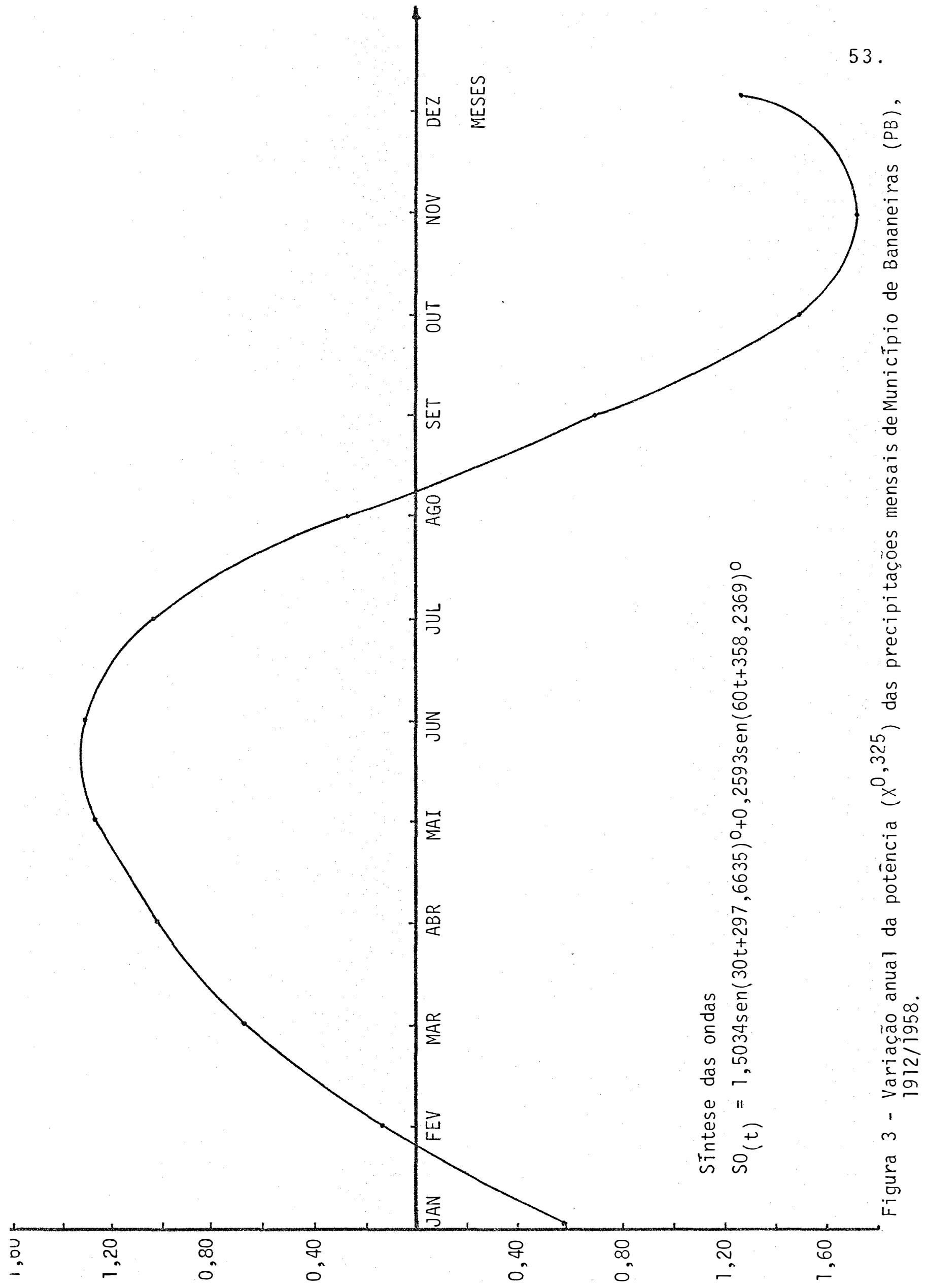



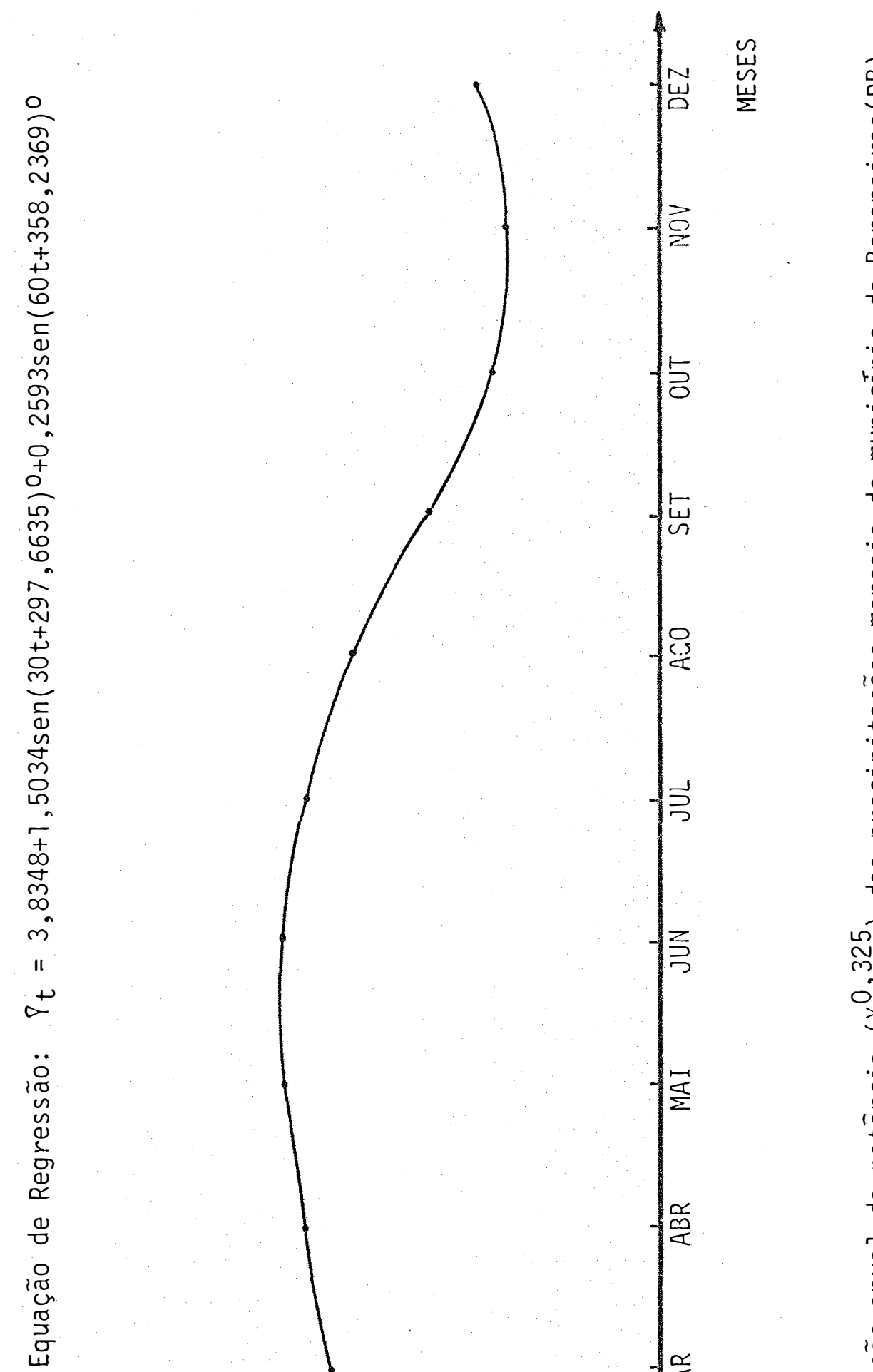

54.

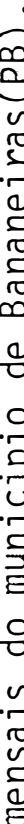

ֻั

凹

Un

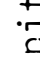

.

ปั

ก

$\stackrel{\sim}{\sim}$

$m$

$0^{\circ}$

0
0
$\frac{0}{c}$
10
+1
0

중

莡

○

iा न

un

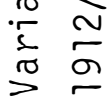

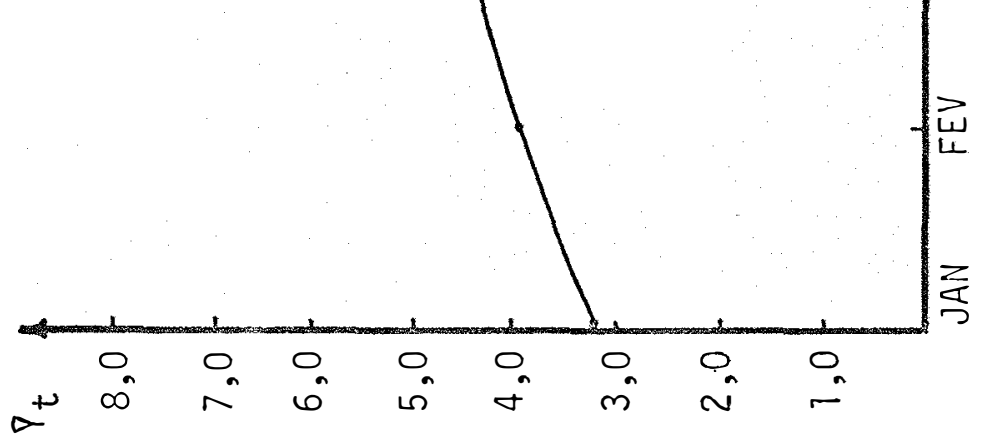

1

$\checkmark$

尔 


\section{CONCLUSOES}

A partir das análises efetuadas nopresente tra balho pode-se chegar às seguintes conclusões:

1. A equação de regressão estimada a partir da transformação $x^{0}{ }^{325}$, para uma série de 47 anos foi:

$\tilde{y}_{t}=3,8348+1,5023 \operatorname{sen}(30 t+297,6635)+0, \angle 593 \operatorname{sen}(60 t+358,2369)$ $\bar{y}_{t}=\bar{p}_{i}$, onde $\bar{\beta}_{i}$ representa precipitação mensal em mm.

2. A onda anual é responsāvel por $96,29 \%$ da variação total anual das precipitações.

3. Bananeiras apresenta um perīodo chuvoso de março a agos to, responsāvel por $62,65 \%$ da precipitação.

4. 0 modelo explica $99,15 \%$ da variação das precipitações plü viais mensais no municipio de Bananeiras. 


\section{BIBLIOGRAFIA}

AMARAl, E., 1968. Anālise Harmōnica. Pes. Agr. Br., 3: 7-43.

Aliaral, E., 1975. Anālise Harmōnica e Previsão a longo prazo. Anais da reunião Internacional de Biometria. Piracicaba SP, p. 232-271.

ANDERSON, T.W., 1971. The statistical analysis of time series. New York, John Wiley and Sons, 704 p.p.

BLISS, C.I., 1958. Periodic regression in Biology and Climato logy. New Haven. Connections Agr. Exp. Station. 55 p.p. (B०1.615).

BRASIL, Ministério do Interior, DNOCS, 1969. Observações pluviométricas do Nordeste do Brasil. Fortaleza, 176 p.p.

BROOKS, C.E. e N. CARRUTHERS, 1953. Handbook of Statistical methods in meteorology. London, Her marjesty's stationery office. 412 p.p. 
COELho, H., 1980. Emprego da anālise harmónica a dados de pro dução de citrus (Cit九us sinensis L. Osbeck). Piracicaba SP. 124 p.p. (Dissertação de Mestrado), ESALQ/USP.

CONRAD, V. e L.W. POLLAK, 1950. Methods in climatology. Massachusetts. Harvard University Press. 459 p.p.

DUARTE, G.S., 1981. O emprego da análise harmónica no estudo da incidência da ferrugem alaranjada do cafeeiro (Hemileia vastatrire Berk et Br) no Estado de Minas Gerais. Piracicaba - SP. 72 p.p. (Tese de Doutorado), ESALQ/USP.

DUARTE, G.S. E D. BARBIN, 1975. Curva epidemiológica da Ferrugem alaranjada do cafeeiro na Zona da Mata (M.G.). Anais. da reunião Internacional de Biometria, Piracicaba - SP. p. $167-184$.

FELTRIN, M.A.V., 1980. A anālise harmōnica no estudo das pre cipitações pluviais no município de Bandeirantes, PR, Pira cicaba - SP. 102 P.P. (Dissertação de Mestrado), ESALQ/USP.

GODOY, H.F.; PIMENTEL GOMES e I.R. NOGUEIRA, 1961. Anālise es tatistica de dados pluviomëtricos de Campinas. Bragantia. Campinas, 20(6): $357-371$.

GOMES, M.C.G.; CURI, P.R. e KROLL, L.B., 1975. Transformações aplicáveis a dados pluviométricos. Anais da reunião Internacional de Biometria, Piracicaba - SP. p. 339-345.

PEREIRA, N.S.C., 1978. Regressão periódica aplicada a dados pluviométricos mensais do município de Grajaú - M.A. Piracicaba - SP. 66 p.p. (Dissertação de Mestrado), ESALQ/USP. 
SPIEgEL, M.R., 1976. Anālise de Fourier. São Paulo. McGrawHill do Brasil, 249 p.p. (coleção Schawn).

THIEBAUT, J.T., 1976. O emprego da anälise harmōnica no estu do das precipitaçöes mensais do município de Viçosa (M.G.). Piracicaba - SP. 92 p.p. (Dissertação de Mestrado). ESALQ/ USP. 
7. APEMDICES 
Apêndice 1 - Valores originais das precipitações pluviais men sais (em mm) no municipio de Bananeiras ( $\mathrm{Pb}$ ), du rante o periodo de 1912-1958.

\begin{tabular}{|c|c|c|c|c|c|c|c|c|c|c|c|c|}
\hline ANOOS & JAiv & FEV & MAR & $A B R$ & MAI & Juir & JUL. & $\mathrm{ACO}$ & SET & G.1T & nov & bez \\
\hline 1912 & 85,5 & 204,3 & 143,1 & 128,3 & 273,6 & $167,5^{=}$ & 85,5 & 141,0 & 93,4 & 24,3 & 94,7 & 12 \\
\hline 1913 & $24 ; 8$ & 291,5 & 176,1 & 122,5 & 120,3 & 148,1 & 261.7 & 153,9 & 37,3 & 32,3 & 0,0 & $? ;, y$ \\
\hline 1914 & 126,4 & 26,9 & 182,9 & 151,3 & 170,9 & 371,8 & 238,2 & 429,5 & 31,6 & 15,1 & 11,8 & $2 \pi, 1$ \\
\hline 1915 & 52,7 & 11,4 & 33,2 & 58,8 & 139,4 & $18: 3,7$ & 134,5 & 140,7 & $2.1,8$ & 0,4 & 11,4 & $i s, j$ \\
\hline 1916 & 18,7 & 55,5 & 217,4 & 176,6 & 181,8 & 147,2 & 53,2 & 21,7 & 2,3 & 9,1 & 4,0 & 20.7 \\
\hline 1917 & 132,2 & 301,2 & 346,0 & 64,2 & 133,6 & 134,8 & 131,6 & 39,2 & $71,6$. & 3,3 & 33,9 & 23,5 \\
\hline 1918 & 91,4 & 106,2 & 36,4 & 110,4 & 147,5 & 116,7 & 32,7 & 41,9 & 18,5 & 4.8 & 1,0 & 3.0 \\
\hline צופו & 12,6 & 17,1 & 13,1 & 39,5 & 18,5 & 49,6 & 164,6 & 179,5 & 154,5 & 46,2 & 11,8 & (b), 0 \\
\hline 多 & 47,9 & $\varepsilon, 4$ & 198,8 & 123,4 & 103,7 & 191,9 & 259,6 & 12.6 & $21, \%$ & 65.2 & 11,7 & $1 \%, 1$ \\
\hline Baci & $\mid x, 2,1$ & $+7,2$ & 204,7 & 149,8 & 225,3 & 194,3 & 201,6 & $10,3,0$ & $\varepsilon 8, \&$ & 11,6 & 12,3 & {$[1,0)$} \\
\hline 1922 & 70,0 & 30,8 & 52,2 & 247.2 & 214,4 & 238,8 & 257,9 & 235,2 & 18.1 & 3,3 & 50.1 & 0.1 \\
\hline 1923 & 46,8 & 123,1 & 29,6 & 97,4 & 51,2 & 219,5 & 179,4 & 50,6 & $36, E$ & 10,3 & 44,9 & lie,s \\
\hline 1924 & $21, \overline{6}$ & 198,0 & 258,5 & 499,7 & 333,1 & 242.7 & 119,5 & 125,9 & 40,4 & 27.6 & 27,5 & $16, z$ \\
\hline lycs & $5 t, 6$ & 50,9 & 131,5 & $23 ., 3$ & 177,2 & $14 \pi, ?$ & 114,2 & $y y_{1}, 2$ & $1 \% 2.4$ & $k, \vdots$ & 3,1 & $\therefore, u$ \\
\hline 1926 & 46.2 & 232,8 & 198,2 & 152,7 & 92,5 & 143,3 & 70,6 & 52,6 & 43,0 & 0.0 & 7.3 & 16,3 \\
\hline $19 ? 7$ & 33,5 & 183,3 & 105,5 & 154,9 & 125,2 & 72,5 & 251,8 & 49,2 & 30,5 & 5,5 & 0,6 & 15,2 \\
\hline 1928 & 84,3 & 13,9 & 185,4 & 173,8 & 140,8 & 122,3 & 124,7 & 43,3 & 93,8 & 14,6 & Wu, & $16, \dot{x}$ \\
\hline 1929 & $3 !, 2$ & 142,1 & 285,8 & 101,4 & 120,1 & 131,3 & 149,9 & 92,00 & 45,7 & 14.7 & 11,0 & 77,7 \\
\hline 1930 & 57,7 & 3,1 & 63,3 & 0,0 & 0,0 & 179,8 & 182,4 & 17,6 & 4,0 & l゙,? & $10, ?$ & $u, u$ \\
\hline 1931 & 56,5 & 237,7 & 135,0 & 217,1 & 226,0 & 455,8 & 158,7 & 252,2 & 159,0 & 33.5 & 16,3 & $3 x, x^{2}$ \\
\hline 1932 & 174,2 & 34,3 & 81,9 & 105,4 & 139,4 & 183,3 & 163,5 & 15,6 & 108,3 & 10,4 & 0,0 & 2,0 \\
\hline 1933. & $|\in|, 3$ & 83,0 & 25,8 & 273,2 & 100,0 & 78,1 & 63,1 & 13,3 & 22,2 & $\%, 0$ & 7,5 & 30.1 \\
\hline 1334 & $\because, 2$ & $(j), 8$ & 285,5 & 62,7 & 249,6 & 54,7 & 18,8 & 58,4 & 15,1 & $\left.3^{\prime}\right), i$ & 12,5 & 61,0 \\
\hline 1935 & 14,4 & 110,9 & 230,6 & 275,4 & 194,7 & 170,6 & 157,2 & 84,6 & 9,5 & 17,3 & 57,4 & 5,4 \\
\hline 1936 & 183,8 & 239,0 & 79,4 & 52,5 & 254.1 & 288,8 & 139,2 & $\mid \beta, 1$ & 18,6 & 23,0 & 0,0 & 0,0 \\
\hline 1937 & 2,0 & 23,0 & 57,0 & 300,4 & 141,9 & 76,5 & 68,1 & 67,2 & 7,9 & 10,1 & $\varepsilon, \epsilon$ & 16,3 \\
\hline 1938 & 27,1 & 6,5 & 178,0 & 122,3 & 146.7 & 62,4 & 36,6 & 146,3 & 60,6 & 18,6 & 35,7 & $3+i, i$ \\
\hline 1939 & $15, \tilde{c}$ & 169,6 & 140,0 & 54,8 & 77,6 & 14,5 & 189,6 & 295,1 & 37,2 & 95,1 & 93,1 & $2 \therefore .9$ \\
\hline 1940 & 113,2 & 232,6 & 232,5 & 275,6 & 374,3 & 232,2 & 184,1 & 130,7 & 78,3 & 10,3 & 5,0 & it,$i t$ \\
\hline 1941 & 0,0 & 28,9 & 284,0 & 299,1 & 111,7 & 99,9 & 132,8 & 132,1 & 32,2 & $A i, 0$ & 37,5 & 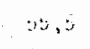 \\
\hline 1942 & 3,2 & 104,2 & 108,5 & 160,3 & 286,5 & 55,5 & 95,6 & 120,3 & 20,0 & 30,7 & 3,2 & $a, y$ \\
\hline 1943 & 72,9 & 18,0 & 100,6 & 50,9 & 138,8 & 99,6 & 215,2 & 68,1 & 47,8 & 0,0 & 16,7 & $13, i$ \\
\hline 1944 & 73,2 & 17,9 & 66,5 & 165,7 & 202,7 & 100,6 & 149,5 & 88,1 & 97,1 & 30,0 & 29,2 & $0 .+4$ \\
\hline 1945 & 54,6 & 191,6 & 72,9 & 80,1 & 295,7 & 263,8 & 170,4 & 131,6 & 62,4 & 33,4 & 51,0 & $17 . i$ \\
\hline 1946 & 219,2 & 46,0 & 190,4 & 121,3 & 156,8 & 108,8 & 66,9 & 55,8 & 19,3 & 9,0 & 11,8 & yo, 3 \\
\hline 15,47 & 100,1 & 72,5 & 254,0 & 98,3 & 213,0 & 226,1 & 147,1 & 54,2 & 42,7 & 7,0 & $\{3, k$ & $m, n, ;$ \\
\hline Istit & 24,1 & 14,6 & 162,2 & 115,3 & 210,0 & 195,6 & 304,8 & 121.7 & 85,1 & 16,0 & 40,5 & $1 x, 7$ \\
\hline 1949 & 38,2 & 8,5 & 56,6 & 209,4 & 251,2 & 201,1 & 73,8 & 144,9 & 70,6 & 49,1 & 68,8 & 11,1 \\
\hline 1950 & 49,8 & 53,0 & 227,7 & 335,0 & 188,9 & 123,8 & 156,5 & 159,0 & 45,8 & 0,0 & 0,0 & $\therefore, 3$ \\
\hline 1951 & 22,2 & 43,5 & 48,8 & 77,0 & 125,3 & 647,1 & 92.2 & 23,0 & 0,0 & 0,0 & 66,6 & $: 35.1$ \\
\hline 1952 & 24,0 & 0,0 & 114,5 & 92,3 & 97,0 & 238,3 & 35,0 & 135,7 & 42,3 & 0,0 & 12,5 & $+4 .:$ \\
\hline 1953 & 47,8 & 0,0 & 43,1 & 154,3 & 152,5 & 304,4 & 211,3 & 123,4 & 0,0 & $0,1)$ & 12,0 & $11, u$ \\
\hline 1954 & 0,0 & 5,0 & 59,3 & 47,1 & 418,6 & 210,3 & 101,5 & $2 \vec{E}, 2$ & 23,3 & 0,0 & 0,0 & $(i, 0)$ \\
\hline 1955 & 0,0 & 167,2 & 254,9 & 166,4 & 175,8 & 137,2 & 82,7 & 59,7 & 86,0 & 89,9 & 0,0 & $n, 0$ \\
\hline 1956 & 32,5 & 115,2 & 236,9 & 250,8 & 119,4 & 214,0 & 165,3 & 214,6 & 46,3 & 19,5 & 0,0 & 14,5 \\
\hline 1957 & 68,1 & 7,1 & 182,0 & 327,1 & 37,4 & 89,5 & 81,1 & 63,5 & 6.7 & 88,0 & 0,0 & 194,2 \\
\hline 1958 & 24.5 & 17,7 & 7,0 & 24,0 & 313,3 & 134,8 & 278,8 & 84,1 & 28,2 & 0,0 & 0,0 & 0,0 \\
\hline
\end{tabular}


Apēndice 2 - Valores das precipitações pluviais mensais em Ba naneiras-Pb, reduzidos para meses de 30 dias, pa ra o período de 1912-1958.

\begin{tabular}{|c|c|c|c|c|c|c|c|c|c|c|c|c|}
\hline ANUS & JAK & IEV & MAR & $A B R$ & MAL & WWN & JUL & $A G O$ & SEY & OUt & NoY. & DE? \\
\hline 1912 & 82,7 & 211,3 & 133,5 & 123,3 & 264.7 & 167,5 & 82,7 & 142,2 & 93,4 & 25,3 & 94,7 & 12,1 \\
\hline 1913 & 24.0 & 312,3 & 170.4 & 122,5 & 116,4 & 143,1 & 253,2 & 143,9 & 37,3 & 31,2 & 0,0 & 27,9 \\
\hline 1914 & 122,3 & 28,8 & 171,0 & 151,3 & 165,4 & 371,0 & 230,5 & 415,6 & 31,6 & 14,6 & 11,8 & 26,2 \\
\hline 1915 & 51,0 & 12,2 & 32,1 & 55,8 & $13.8,9$ & 153,7 & 130,2 & 136,1 & 21,3 & 0,3 & 11,4 & 40,1 \\
\hline 1916 & 18.1 & 57,7 & 210,3 & 176,6 & 175,9 & 197,2 & 51,4 & 20,9 & 2,3 & 8,8 & 4,0 & 20,0 \\
\hline 1917 & 127,9 & 332,7 & 334,8 & 64,2 & 129,3 & 134,8 & 127,3 & 37,9 & 21,6 & 3,2 & 33,9 & $22, i$ \\
\hline 1918 & 88,4 & 113,8 & 35,2 & 110,4 & 142,7 & 116,7 & 31,6 & 40,5 & 18,5 & 4,6 & 1.6 & 2,9 \\
\hline 1919 & 12,2 & 18,3 & 12,6 & 39,5 & 17,9 & 49,6 & 159,2 & 173,7 & 154,5 & 44,7 & 11,8 & 58,1 \\
\hline 1920 & 46,3 & 6,6 & 192,4 & 123,4 & 100,3 & 191,9 & 251,2 & 12,2 & 21,7 & 63,1 & 11,7 & 114,3 \\
\hline 1921 & 156,8 & 104,1 & 198,1 & 149,8 & 210,0 & 144,3 & 195,1 & - 99,6 & 89,9 & 10,6 & 42,3 & 41,6 \\
\hline 1922 & 67,7 & 33,0 & 50,5 & 247,2 & 207,4 & 238,8 & 249,5 & 227,6 & 18,1 & 3,2 & 50,1 & 0,1 \\
\hline 1923 & 45,3 & 131,9 & 28,6 & 97,4 & 49,5 & 214,5 & 173,6 & 48,9 & 36,6 & 9,9 & 44,9 & 9,9 \\
\hline 1924 & 20,1 & 194,5 & 250,2 & 449,7 & 322,3 & 242,4 & 115,6 & 121,8 & 46,4 & 26.7 & 27,5 & 14,7 \\
\hline 1325 & 54.7 & 54,5 & 127,2 & 234,3 & 142,4 & 144,0 & 110,5 & 92,1 & 122,4 & 10,2 & 9,1 & 17,4 \\
\hline 1926 & 44,7 & 249,4 & 191.6 & 152,7 & 89,6 & 143,3 & 68,3 & 50,9 & 43,0 & 5.8 & 7,5 & 17,8 \\
\hline 1927 & 32,4 & 196,4 & 102.1 & 154,9 & 121,2 & 72.5 & 243,6 & 47,6 & 30,5 & 5,3 & 0,6 & 12,7 \\
\hline 1928 & 81,6 & 14,4 & 179,4 & 173,9 & 135,2 & 122,3 & 120,6 & 41,9 & 93,8 & 14,1 & 10.7 & 10,1 \\
\hline 1929 & 39,2 & 152,1 & 276,5 & 101,4 & 116,2 & 131,3 & 145,1 & 89.6 & 45,7 & 13,6 & 11,6 & 75.2 \\
\hline 1930 & 55,8 & 37,6 & 61,2 & 0,0 & 0,0 & 174,8 & 176,5 & 17,2 & 4,6 & 18,1 & 10,2 & 0,5 \\
\hline 1931 & 54,7 & 254,7 & 130.6 & 217,1 & 213,7 & 455,8 & 153,5 & $24: 4,1$ & 159,6 & 32.7 & 16,3 & 50,5 \\
\hline 1932 & 168,6 & 33,5 & 79,2 & 105,4 & 134,9 & 183,8 & 158,2 & 15,1 & 105.3 & 15,8 & 6,0 & 1,9 \\
\hline 1933 & 156.1 & 88,9 & 24,9 & 273,2 & 96,7 & 78,1 & 61,1 & 12,8 & 22,2 & 6,7 & 7,5 & 29,1 \\
\hline 1934 & 3,1 & 115,5 & 275,3 & 62,7 & 241,5 & 54,7 & 18,2 & 56,5 & 15.1 & 29,6 & 12,5 & 59,0 \\
\hline 1935 & 13,9 & 118,8 & 223,2 & 275,4 & 188,4 & 170,6 & 152,1 & 81,8 & 9,5 & 16,7 & 57.4 & 5,6 \\
\hline 1936 & 18,2 & 247,2 & 76,8 & 52,5 & 245,9 & 288,9 & 134.7 & 17,5 & 18,6 & 28,6 & 0,0 & 0,0 \\
\hline 1937 & 1,9 & 24,6 & 55,1 & 300,5 & 137,3 & 76,5 & 65,9 & 65,0 & 7,9 & 14,6 & 6,6 & 18,2 \\
\hline 1933 & 26,2 & 6,9 & 172,2 & 122,3 & 141,9 & 62,4 & 35,4 & 141,5 & 60,6 & 17,9 & 35,7 & 32,9 \\
\hline 1939 & 15,1 & 181,7 & 135,4 & 54,8 & 75.1 & 14,5 & 183,4 & 285,5 & 37,2 & 92,0 & 93,1 & 27,9 \\
\hline 1940 & 109,5 & 240,6 & 225,0 & 275,6 & 362,2 & 232,2 & 178,1 & 126,4 & 78,3 & 9,9 & 5,6 & 44,5 \\
\hline 1941 & 0,0 & 30,9 & 278,8 & 299,1 & 107,9 & 99,9 & 128,5 & 127,8 & 32,2 & 42,5 & 37,5 & 53,7 \\
\hline 1942 & 3,1 & 111,6 & 105,0 & 160,3 & 277,2 & 55,5 & 92,5 & 116,4 & 20,0 & 23,7 & 3,2 & 21,2 \\
\hline 1943 & 70,5 & 19,3 & 97,3 & 50,9 & 134,2 & 99,5 & 208,2 & 65,9 & 47,8 & 0,0 & 16,7 & 12,9 \\
\hline 1944 & 70,8 & 18,5 & 64,3 & 165,7 & 196,2 & 160,6 & 194,6 & 85,2 & 97.1 & 34,8 & 29,2 & 6,2 \\
\hline 1945 & 52,8 & 205,3 & 70,5 & 80,1 & 286,2 & 263,8 & 164,9 & 127.3 & 62,4 & 32,3 & 51,0 & 17,0 \\
\hline 1946 & 212,1 & 49,3 & 184,2 & 121,3 & 151,7 & 108,8 & 64,7 & 53,9 & 19,3 & 9,2 & 11,8 & 93,1 \\
\hline 1947 & 96,8 & 77,6 & 245,8 & 98,3 & 206,1 & 226,1 & 142,3 & 52,4 & 42,7 & 6,7 & 83,8 & 95,3 \\
\hline 1948 & 23,2 & 15,1 & 156,9 & 115,3 & 203,2 & 195,6 & 294,9 & 117,7 & 85,1 & 16,1 & 46,5 & 19,1 \\
\hline 1949 & 36,9 & 9,1 & 54,7 & 209,4 & 243,1 & 201,1 & 71,4 & 140,2 & 70,6 & 47,5 & 68,8 & 10,7 \\
\hline 1950 & 48,2 & 56,7 & 220,3 & 335,0 & 122,8 & 123,8 & 151,4 & 153,8 & 45,8 & 0.0 & 0,0 & 77,7 \\
\hline 1951 & 21,5 & 46,6 & 47,2 & 77.0 & 121,2 & 647,1 & 89,2 & 22,2 & 0,0 & 0,0 & 66,0 & 80,4 \\
\hline 1252 & 23,8 & 0.0 & 110,8 & 92,8 & 93,8 & 238,3 & 33,8 & 131,3 & 42,3 & 0,0 & 12,5 & 38,9 \\
\hline 1953 & 46,2 & 0,0 & 41,7 & 154,3 & 147,5 & 304,4 & $20,3,4$ & 119,4 & 0,0 & 0,0 & 12,0 & 0,0 \\
\hline 1954 & 0.0 & 5,3 & 57,3 & 47,1 & 405,1 & 210,3 & 98,2 & 25,3 & 23,3 & 0,0 & 0.0 & 0,0 \\
\hline 1955 & 0.0 & 179,1 & 216,6 & 166,4 & 170,1 & 137,2 & $8 \cap, 0$ & 57,7 & 86,0 & 85,9 & 0.0 & 0,0 \\
\hline 1955 & 31,4 & 119.2 & 223.2 & 250,6 & 115,5 & 214,0 & 155,9 & 207.6 & 45,3 & 18,8 & 0,0 & 14,0 \\
\hline 1957 & 65,3 & 7,6 & 176.1 & 327.1 & $35, ?$ & 83,5 & $7 B, 4$ & 61,4 & 6,7 & 8,5 & 0.0 & 187.9 \\
\hline $195 \%$ & 23.7 & 18,9 & 6,7 & 24,0 & 303,2 & 134,8 & 267,8 & 81,4 & 28.2 & 0,0 & 0,0 & 0,0 \\
\hline
\end{tabular}


Apēndice 3 - Valores das potências $\left(Z=x^{0,325}\right)$ das precipita ções pluviais mensais (em $\mathrm{mm}$ ) reduzidas a meses de 30 dias no municipio de Bananeiras ( $\mathrm{Pb}$ ) duran te o período de 1912-1958.

\begin{tabular}{|c|c|c|c|c|c|c|c|c|c|c|c|c|}
\hline Anos & JAN & FEV & MAR & $A B R$ & $\operatorname{mil}$ & Juit & JUL. & AGO & SET & 047 & wor & $0 x_{2}^{\prime}$ \\
\hline 1912 & 4,199 & 5,693 & 4,965 & 4,843 & 6.129 & 5,282 & 4,199 & 5,0138 &,+ 308 & $\therefore, 750 \%$ & 4.338 & $2,24 i$ \\
\hline 1913 & 2,809 & 6,467 & 5,311 & 4,771 & 4.692 & 5,074 & 6,041 & 5,083 & 5,251 & 3,059 & 0,1000 & $\therefore, y 4$ \\
\hline 1914 & 4,765 & 2,980 & 5,377 & 5,110 & 5,260 & 6,844 & 5,859 & 7,096 & 3.071 & $2,391 \mathrm{j}$ & 2,230 & ?, ist \\
\hline 1915 & 3,588 & 2,254 & 3,087 & 3,695 & 4,923 & 5,442 & 4,806 & 4,937 & 2.722 & 0.676 & 2,205 & 3,319 \\
\hline 1916 & 2,562 & 3,729 & 5,687 & 5,373 & $5,36 \varepsilon$ & 5,064 & 3,598 & 2,685 & 1.310 & 2,027 & 1,509 & $2,0,7$ \\
\hline 1917 & 4,838 & 6,536 & 6,615 & 3,867 & 4,855 & 4,922 & 4,831 & 3,258 & $4, \ldots i\}$ & $1,40 y$ & $3,1+2$ & $2,7 \leqslant 0$ \\
\hline 1918 & 4,291 & 4,658 & 3,181 & 4,612 & 5,014 & 4,696 & 3,071 & 3,329 & $2,50 !$ & 1,842 & 1,165 & 1,413 \\
\hline 1919 & 2,254 & 2,572 & 2,278 & 3,302 & 2,553 & 3,556 & 5,195 & 5,344 & 5,745 & 3,432 & 2,230 & $3,21+4$ \\
\hline rests & $3.4 \%$ & 1. iste & 5,525 & 4,782 & 4,471 & 5,520 & 6,025 & 2,254 & 2,718 & $3, \ddot{C}+\dot{L}$ & 2,224 & $\sqrt[3]{1006}$ \\
\hline 1921. & 5,164 & 4,525 & 5,574 & s, & 5,683 & 5,032 & 5,550 & A. 4 E I & 4,247 & 2,103 & 3,377 & 3,34 \\
\hline 1922 & 3,934 & 3,115 & 3,577 & 5,994 & $5,6 \in 1$ & 5,927 & 6,012 & 5,635 & 2,502 & 1, y & 3,560 & $6, i n s$ \\
\hline 1923 & 3,153 & 4,887 & 2,973 & 4,428 & 3,554 & 5,724 & 5,343 & 3,540 & 3,222 & 2.100 & 3,443 & $2,1,6$ \\
\hline 1924 & 2,651 & 5,544 & 6,017 & 7,281 & 6,534 & 5,956 & $4, E B 2^{\prime \prime}$ & 4.702 & $3,4 \leq 0$ & $2, \omega_{2}$ & 2,436 & 2,50 \\
\hline 1923 & 3,677 & 3,067 & 4,830 & 5,890 & 5,010 & 5,028 & 4,614 & 4,348 & 4,770 & 6.127 & $x, 0+3$ & $\therefore \therefore$ \\
\hline 1926 & 3,438 & 6,011 & 5,519 & 5,125 & 4,310 & 5,020 & $3,94 i$ & $3,5,0$, & נו5 & 1,770 & $1.9 \%$ & $\because \therefore$ \\
\hline 1927 & 3,096 & 5,562 & 4,497 & 5,149 & 9,754 & 4,023 & 5,965 & $3,50 \%$ & 3,030 & 1,713 & $0, s ; 7$ & $\therefore, \cdots$ \\
\hline 1928 & 4,181 & 2,379 & 5,401 & 5,346 & 4,938 & 4,768 & 4,741 & 3,350 & $4,37 \%$ & 2,303 & 2,160 & $2,1,0$ \\
\hline$I^{\prime} z^{\prime} z^{\prime} y$ & 3,0326 & 5,119 & 6,216 & 4,487 & 4,690 & 4, \&\&० & $5,0.81$ & 4,310 & 3,463 & 2,335 & 2,217 & 4,071 \\
\hline 1530 & $3, E 95$ & 3,250 & 3,807 & 0,000 & 0,000 & 5,355 & 5,312 & 2,520 & $1,0.2$ & 8,50 & 2,127 & U, is: \\
\hline 19 & $3,6,7\}$ & 6,052 & 4,871 & 5,746 & 5,760 & 7,313 & 5,134 & 4,969 & 5.195 & 3,100 & $2, * 17$ & 3,577 \\
\hline 1932 & $5,2 y j$ & 3,190 & 4,140 & 4,543 & 4,923 & 5,443 & 5,184 & 2,416 & 4,584 & 2.452 & $1,7 \mathrm{yg}$ & 1,231 \\
\hline$y_{1}:$ & ri, ied & 4,239 & 2,842 & 6,192 & 4,418 & 4,122 & 3,805 & 2,290 & $2,7 \mathrm{st}$ & T, & 1,964 & $\therefore, i \neq h$ \\
\hline 1934 & 1,464 & 1,681 & 6,215 & 3,838 & 5,949 & 3,671 & $2,56 \%$ & 3,710 & 2,016 & 3,001 & 2,27 & $3,76.2$ \\
\hline 1935 & 2,352 & 4,724 & 5,798 & 6,208 & $5,48 \%$ & 5,373 & 5,119 & 4,184 & 2,078 & $2,+4 k$ & $3,7 \% 3$ & $1,7.60$ \\
\hline 1936 & 2,567 & 6,199 & 4,099 & 3,622 & 5,981 & 6,205 & 4,920 & 2,585 & 2,973 & 2,439 & 0,000 & $0,(j): 1$ \\
\hline 1937 & 1,231 & 2,831 & 3,680 & 6,386 & 4,951 & 4,094 & 3,900 & 3,383 & 1,947 & 2,390 & 1,840 & 2,567 \\
\hline 1938 & 2,890 & 1,873 & 5,329 & 4,768 & 5,004 & 3,832 & 3,187 & 5,000 & 3,795 & $2,5,53$ & 3,196 & 3.112 \\
\hline 1934 & 2,416 & 5,423 & 4,263 & 3,473 & $4, \Omega(1)$ & 2,334 & 5.440 & 6,201 & 3,239 & 9,347 & 4,36 & $2, y, y$ \\
\hline 1940 & 4,600 & 5,941 & 5,813 & 6,209 & 6,780 & 5,873 & $5,38 \mathrm{~s}$ & 4,820 & 4.125 & $\therefore$ lue & $1, i \omega i$ & A. is \\
\hline 1941 & 0,000 & 3,049 & $6,204$. & 6,377 & 4,578 & 4,965, & 4,8346 & 4,837 & $3,0, Y 00$ & 3,382 & 3,247 & S. \\
\hline 1942 & 1,444 & 4,629 & 4,538 & 5,207 & 6,221 & 3,688 & 4,355 & 4,692 & 2,647 & & $1.45 y$ & 2.834 \\
\hline 1943 & 3,987 & 2,617 & 4,427 & 3,586 & 4,914 & 4,461 & 5,668 & 3,900 & 3,514 & 0,000 & $2,+96$ & 2,295 \\
\hline $1944^{\circ}$ & 3,992 & 2,581 & 3,869 & 5,263 & 5,560 & 5,210 & 5,035 & 4,200 & $4,4<4$ & 3,1603 & 2,993 & 1,6093 \\
\hline 1945 & 3,629 & 5,643 & 3,987 & 4,156 & 6,286 & 6,122 & 5,255 & 4,837 & 3,2432 & 3,093 & 3,5is & 2,511 \\
\hline 1946 & 5,703 & 3,549 & 5,447 & 4,756 & 5,114 & 4,590 & 3,877 & 3,653 & 2,617 & 2,056 & 2,230 & $\therefore, 304$ \\
\hline 1947 & 4,419 & 4,113 & 5,983 & 4,442 & 5,650 & 5,823 & 5,009 & 3,620 & 3,387 & 1,855 & 4,217 & $\therefore, 397$ \\
\hline 1948 & 2,778 & 2,416 & 5,17 ו & 4,678 & 5,624 & 5,555 & 6,348 & 4,709 & 4,238 & 2,457 & 3,482 & $2, \cos \theta$ \\
\hline 1949 & 3,230 & 2,049 & 3,671 & 5,679 & 5,961 & 5,605 & 4,003 & 4,985 & $3,9 \cup i r$ & 3,506 & $3,45 i$ & $\therefore, 100$ \\
\hline 1950 & 3,523 & 3,714 & 5,774 & 6,616 & 5,434 & 4,487 & 5,111 & 5,137 & 3,465 & 0,060 & 0,000 & 4.115 \\
\hline 1951 & 2,710 & 3,485 & 3,499 & 4,103 & 4,754 & 8,195 & 4,303 & 2,733 & 0,000 & 0,000 & $3,90 ?$ & 4,161 \\
\hline 1952 & 2,801 & 0,000 & 4,618 & 4,359 & 4,374 & $.5,923$ & 3,139 & 4,880 & 3,377 & 0,000 & 2,272 & 3,280 \\
\hline 1953 & 3,475 & 0,000 & 3,361 & 5,143 & 5,068 & 6,413 & 5.635 & 4,731 & 0,000 & 0,000 & 2,242 & 0,000 \\
\hline 193. & 0,000 & 1,719 & 3,727 & 3,497 & 7,038 & 5,687 & 4,440 & 2,857 & 2,7482 & 0,000 & 0,000 & 0,030 \\
\hline 1955 & 0,000 & 5,398 & 5,989 & 5,270 & 5,308 & 4,950 & 9,159 & 3,375 & 4,253 & 4,267 & 0,000 & 0,00 \\
\hline 1956 & 3,065 & 4,729 & 5,848 & 6,022 & $4,6,81$ & 5,719 & 5,202 & 5,663 & 3,477 & 2,594 & 0,000 & 2,357 \\
\hline 1957 & 3,900 & 1,933 & 5,368 & 6,565 & 3,210 & 4,308 & 4,127 & 3,812 & 1,855 & 2,034 & 0,000 & 5,433 \\
\hline 1958 & 2,797 & 2,529 & 1,855 & 2,809 & 6,405 & 4,922 & 6,161 & 4,177 & 2,960 & 0,000 & 0,000 & $0,0 \wedge 0$ \\
\hline
\end{tabular}




\section{Apēndice 4 - Matriz dos desvios em relação à média ( $Y^{\prime}$ ).}

\begin{tabular}{|c|c|c|c|c|c|c|c|c|c|c|c|}
\hline 0,3646 & 1,8614 & $.1,1307$ & 1,0088 & 2,2942 & 1,4472 & $0,36,46$ & 1,1735 & 0,5339 & $-0,977$ & - E,josi & $-1, \therefore \in 2$ \\
\hline$-1,0256$ & 2,6326 & 1,4768 & 0,9365 & 0,8580 & 1,2401 & 2,2064 & $1,2: 190$ & $-0,5020$ & $-0,7760$ & $-3,2,0$ & $-6.40+4$ \\
\hline 0,9340 & $-0,8542$ & 1,5428 & 1,2755 & 1,4256 & 3,0098 & $2,024.7$ & 3,2621 & $-0,7629$ & $-1,44+7$ & $-1,6 \mathrm{~m}$ & $-0,9+i ;$ \\
\hline$-0,2459$ & $-1,5802$ & $-0,7472$ & $-0,1394$ & 1,0884 & 1,6081 & 1,0320 & 1,1026 & $-1,1121$ & $-3,1536$ & $-1,1635$ & -0.5156 \\
\hline$-1,2718$ & $-0,1053$ & 1,8527 & 1,5388 & 1.5319 & 1,2300 & $-0,2387$ & $-1,1.491$ & $-2,5239$ & $-1,8073$ & $-2,2 \cos x$ & $-1,1875$ \\
\hline 1,0039 & 2,7019 & 2,7805 & 0,0328 & 1,0210 & 1,0872 & 0,9965 & $-0,5700$ & 0,1724 & $-2,3754$ & $-0, r 9 u_{0}$ & $-1,0 \% 00$ \\
\hline 0,4565 & 0,8236 & $-0,6533$ & 0,7779 & 1,1792 & 0,8319 & $-0,7229$ & $-0,5049$ & $-1,2535$ & $-2,1927$ & $-2,009 \%$ & $-2,+213$ \\
\hline$-i, \Xi \pm 00$ & $-1,2 \varepsilon 26$ & $-1,5564$ & $-0,5319$ & $-1,2810$ & $-0,2782$ & 1,3807 & 1,5100 & 1,3103 & $-0,3904$ & -1, w. & $-6,6$ ivic \\
\hline$-0,3569$ & $-1,9882$ & 1,6900 & 0,9179 & 0,6363 & 1,6859 & 2,1900 & $-1,5802$ & $-1,1161$ & 0,0111 & $-1, c r u$ & 0,6303 \\
\hline 1,3351 & 0,6907 & 1,7433 & 1,2589 & 1,8507 & 1,1974 & 1,7157 & 0,6262 & 0,4028 & $-7,06009$ & $-0,5076$ & $-6,470 \leqslant$ \\
\hline 0,1001 & $-0,7193$ & $-0,2573$ & 2,1595 & 1,8270 & 2,0925 & 2,1775 & 2,0007 & $-1,271$ & $-2,3754$ & -0, atio & $-3,3610$ \\
\hline$-0,3815$ & 1,0526 & $-0,8609$ & 0,5939 & $-0,2305$ & 1,8893 & 1,5090 & $-0,2946$ & $-0,6127$ & $-1,7282$ & $-0,301$. & $-1,1242$ \\
\hline$-1,1=30$ & 1,7101 & 2,1830 & 3,4463 & 2,6992 & 2,1214 & 0,8775 & 0,9276 & $-0,3544$ & $-0,9200$ & $-0,8 \mathrm{set}$ & $-1,4354$ \\
\hline$-0,1632$ & $-0,1676$ & 0,9953 & 2,0560 & 1,1758 & 1,1940 & 0,7793 & 0,5141 & 0,9313 & $-1,7070$ & $-1,7351$ & $-1,3 \operatorname{sinti}$ \\
\hline$-0,3964$ & 2,1768 & 1,6850 & 1,2908 & 0.4754 & 1,1860 & 0,1114 & $-0,2482$ & $-0,4395$ & $-2,00.92$ & $-1,90 ; y$ & $-1,2007$ \\
\hline$-0,7379$ & 1.7277 & $0,66,22$ & 1,3147 & 0,9200 & 0,1887 & 2.1310 & $-0,3: 7 \%$ & -0.798 & $-2,1153$ & $-2.901 \%$ & 1, sive \\
\hline 0,3463 & $-1,9559$ & 1,5664 & 1,5120 & $1,10 j 8$ & 0,9340 & 0,9123 & $-0,4679$ & $0,5,000$ & $-1, \$ 710$ & $-1,174$ & $-1, i \mid i$ \\
\hline$-0, E 07 £$ & $1,2 \dot{8} 42$ & 2,3817 & 0,6522 & 0,8553 & 1,0453 & $1,206^{\circ}$ & 0,4754 & $-0,3716$ & $-1,+492$ & -1 , ches & 0.2300 \\
\hline - ¿, Ijin & $-0,58.44$ & $-0,0268$ & $-3,83: 4$ & $-3,8348$ & 1,5210 & 1,5378 & $-1,3139$ & $-2,19: 7$ & $-1,2719$ & $-1,70 \%$ & - iduscis \\
\hline$-0,1632$ & $2,21 \varepsilon 0$ & 1,0369 & 1,9118 & 1,9255 & 3,4782 & 1,2995 & $2,33.79$ & $1,30.99$ & $-0,7283$ & $-1,35 \%$ & $-0,2<i=$ \\
\hline$\therefore \therefore$ & $-6,6895$ & 0,3060 & 0,7090 & 1,02284 & $1,6(69)$ & 1,3501 & $-1,41,14$ & 0,743 & $-1, x \in$ & $-\therefore$ untio & $\therefore, 6 \times \cdots$ \\
\hline 1,3276 & $0,46.44$ & $-0,9918$ & 2,3575 & 0,5835 & 0,2872 & $-0,028$ & $-1,5447$ & $-0,0955$ & $-1,9792$ & -1, swy & $-0,1+40$ \\
\hline$-2,39$ & 0,8901 & 2,3803 & 0,0032 & 2,1142 & $-0,1632$ & $-1,2672$ & $-0,1244$ & $-1,4134$ & $-0,4275$ & $-1, \therefore \mathrm{cos}$ & $-0,0 / 18$ \\
\hline$-1,+425$ & 0,6892 & 1,9638 & 2,3737 & 1,6530 & 1,4788 & 1,2842 & 0,3497 & $-1,750 \%$ & $-1,3330$ & $-0,305$ & $\therefore, v i s$ \\
\hline$-1,26,72$ & 2,1595 & 0,2647 & $-0,2119$ & 2,1492 & 2,4703 & 1,0860 & $-1,299_{1} 7$ & $-1,2,990$ & $-0,3009$ & $-3,83+4$ & $-3,83,3$ \\
\hline$-2,6028$ & $-1,0030$ & $-0,1545$ & 2,5515 & 1,1167 & 0,2595 & 0,0658 & $0,0.484$ & $-1,877$ & $-1,44.17$ & $-1,50$ & $-1, K C T L$ \\
\hline$-0,9444$ & $-1,9614$ & 1,4949 & 0,9340 & 1,1700 & $-0,0027$ & $-0,6: 174$ & 1,1654 & $-0,0390$ & $-1,2810$ & $-0,73: 7$ & $-0,7224$ \\
\hline$-1,4184$ & 1,5888 & 1,0943 & $-0,1611$ & 0,2350 & $-1,4500$ & 1,6052 & 2,4468 & $-0,5956$ & 0,5120 & $0,52.4$ & $-0, b e i 0$ \\
\hline 0,7657 & 2,1070 & 1,9789 & 2,3751 & 2,9518 & 2,0388 & 1,5530 & 0,9854 & 0,2900 & $-1,1288$ & $-2,0$ ists & $-0,1014$ \\
\hline$-3,8348$ & $-0,7852$ & 2,3693 & 2,5425 & 0,7437 & 0,6305 & 1,0113 & 1,0027 & $-0,7 ; i 41$ & $-0,4523$ & $-0,5372$ & -0.12302 \\
\hline$-2,3903$ & 0,7942 & 0,7034 & 1,3723 & 2,3868 & $-0,1459$ & 0,5202 & 0,3580 & $-1,8073$ & $-0,8242$ & $-2,5 \%, 4$ & $-1,1 s c 7$ \\
\hline 0,1523 & $-1,2177$ & 0,5924 & $-0,2482$ & 1,0801 & 0,6262 & $1,834 ?$ & 0,0658 & $-0,3207$ & $-3,8348$ & $-1,3300$ & 95:3, \\
\hline 0,1578 & $-1,2537$ & 0,0348 & 1,4287 & 1,7258 & 1.3755 & 1,2008 & 0,4054 & 0,5895 & $-0,6651$ & $-0, c i 0.8$ & $-2,0.13$ \\
\hline$-0,2052$ & 1,8084 & 0,1523 & 0,3212 & 2,4518 & 2,2874 & 1,4204 & 0,9965 & $-0,0027$ & $-0,7410$ & $-0,2.4 \div 9$ & $-1,3253$ \\
\hline 1,8684 & $-0,2852$ & 1,6129 & 0,9213 & 1,2798 & 0,7561 & 0,0426 & $-0,1808$ & $-1,2177$ & $-1,7778$ & $-1,6045$ & u, is \\
\hline 0,5850 & 0,2786 & 2,1484 & 0,6072 & 1,8155 & 1.9882 & 1,1746 & $-0,2141$ & $-0,4472$ & $-1,5792$ & $0,3: 20$ & 0.506 \\
\hline$-0,0564$ & $-1,4184$ & 1,3362 & 0,8435 & 1,7895 & 1,7203 & 2.5132 & 0,8749 & 0,4033 & $-1,3675$ & $-0,3000$ & $-1,2206$ \\
\hline$-0,6042$ & $-1,7851$ & $-0,1632$ & 1,8437 & 2.1270 & 1,7706 & 0,1688 & 1,1505 & 0,1541 & $-0,3278$ & $0,120 x$ & $-1,0743$ \\
\hline$-0,3111$ & $-0,1201$ & 1,9392 & 2,7818 & 1,5994 & 0,9529 & 1,2776 & 1,3027 & $-0,3691$ & $-3,83+3$ & $-3,34 t$ & $0, i w j s$ \\
\hline$-1,1243$ & $-0,3496$ & $-0,3651$ & 0,2682 & 0,9200 & 4,3605 . & 0,4691 & $-1,0959$ & $-3,83: 48$ & $-3,9348$ & 0,0017 & 0, sid \\
\hline$-1,0333$ & $-3,8348$ & 0,7834 & 0,5248 & 0,5400 & 2,0885 & $-0,7950$ & 1,0453 & $-0,4575$ & $-3,8348$ & -1 , sciss & -0.5755 \\
\hline$-0,3593$ & $-3,8348$ & $-0,4732$ & 1,3082 & 1,2334 & 2,5790 & 1,8003 & 0,8963 & $-3,8348$ & $-3,8348$ & $-1,5023$ & $-3,03 . i 4$ \\
\hline$-3,8348$ & $-2,1153$ & $-0,1074$ & $-0,3375$ & 3,2033 & 1,8527 & 0,6057 & $-0,9771$ & $-1,0525$ & $-3,83+5$ & -3, is is & $-3,03.14$ \\
\hline$-3,8348$ & 1,5634 & 2,1547 & 1,4359 & 1.4737 & 1,1155 & 0,3195 & $-0,0990$ & 0,4183 & 0,4327 & $-3,03+i s$ & $-3, k+14$ \\
\hline$-0,7693$ & 0,8984 & 2,0140 & 2,1877 & 0,8461 & 1,8850 & 1,3681 & 1,8288 & $-0,3569$ & $-1,2400$ & $-3,03+6$ & $-1,4770$ \\
\hline 0,0658 & $-1,9016$ & 1,5339 & 2,7307 & $-0,6242$ & 0,4738 & 0,2923 & $-0,0227$ & $-1,9792$ & $-1,8300$ & $-3,3543$ & $1,6+32$ \\
\hline$-1,037$. & $-1,2355$ & $-1,9792$ & $-1,0256$ & 2,5708 & 1,0872 & 2,3323 & 0,3430 & $-0,8745$ & $-3,8348$ & $-3,53.4$ is & $-3,6342$ \\
\hline
\end{tabular}




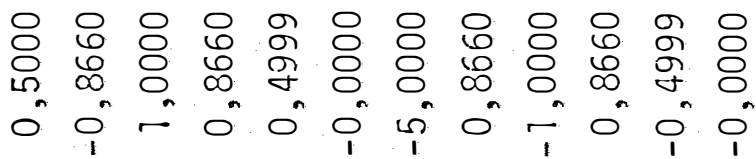

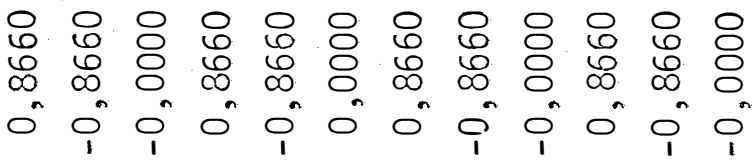

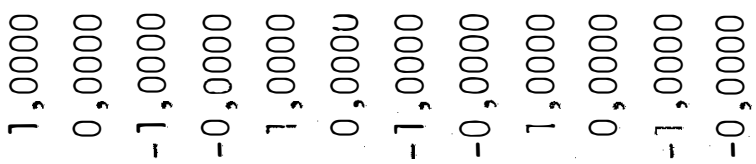

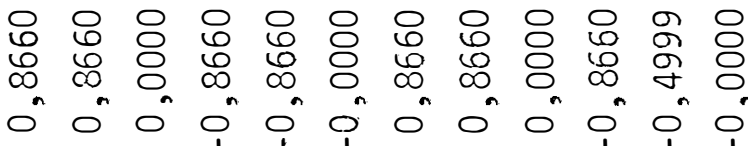

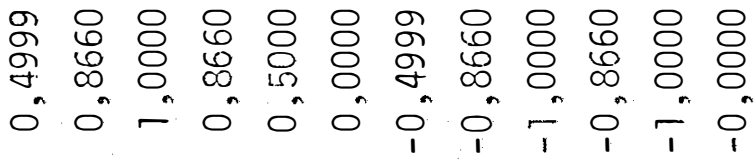

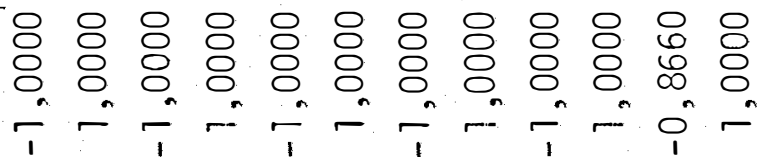

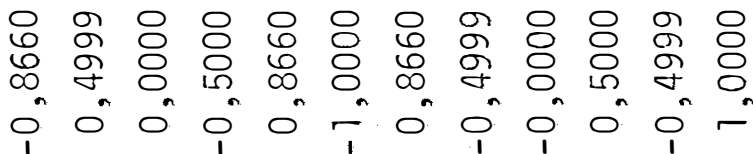

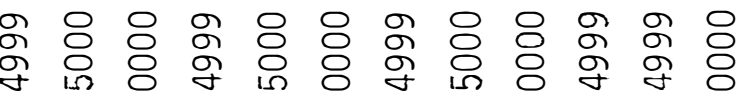
$0^{n} 0^{n}-0^{n} 0^{n}{ }^{n} 0^{n} 0^{n}-0^{n} 0^{n}{ }^{n}-$

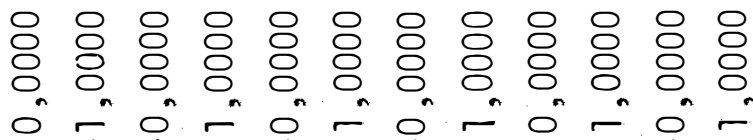

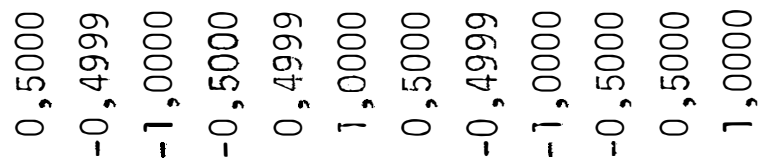

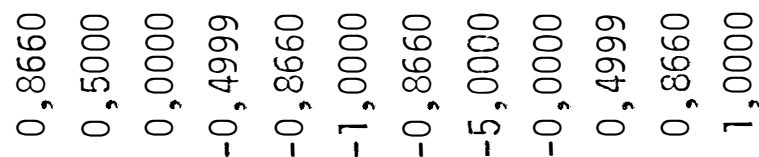




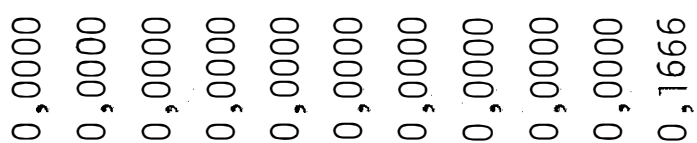

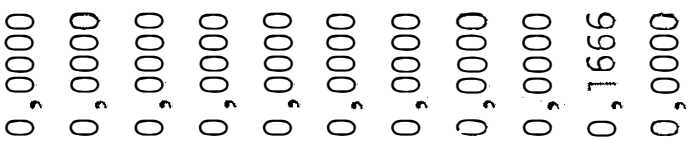

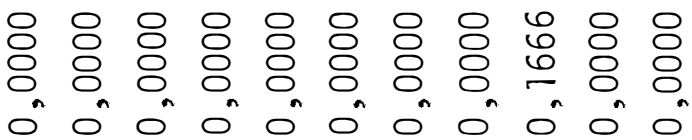

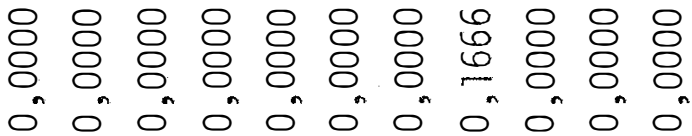

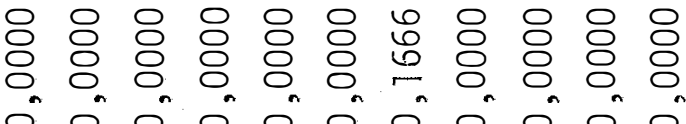

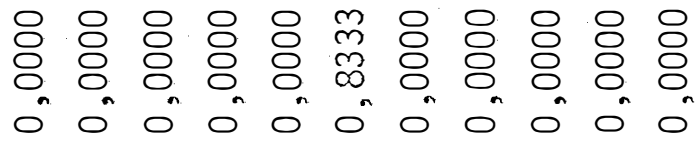

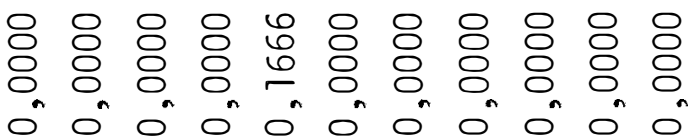

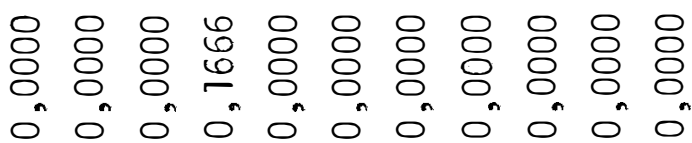
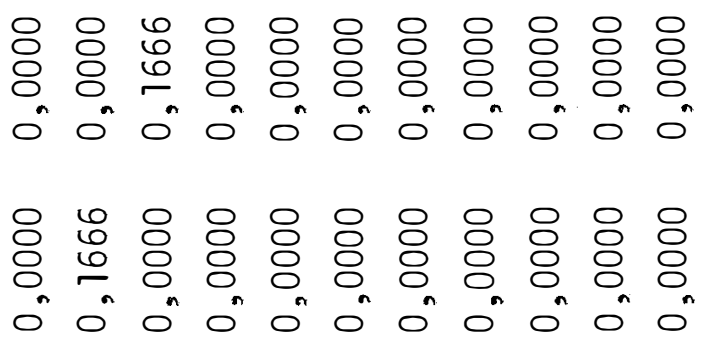

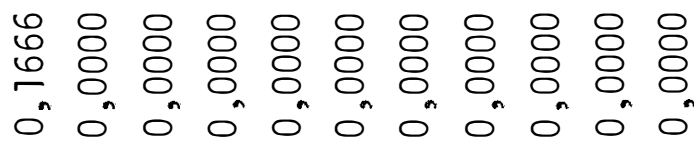


Apēndice 7 - Matriz $\widehat{\beta}^{\prime}$

\begin{tabular}{|c|c|c|c|c|c|c|c|c|c|c|}
\hline$-0,161 ?$ & $.7,75,50$ & $-0,2892$ & $-0,2993$ & $-0,3625$ & $-0,1928$ & 0,6304 & 0,1276 & 0,1906 & $-0,7392$ & $-0,1414$ \\
\hline$-1.5,5.54$ & -0.5746 & $-0,2993$ & 0,0193 & $n .7623$ & 0,4425 & 0,9135 & 1.1371 & $-0,1014$ & 0.0630 & 0,0198 \\
\hline$-1,9233^{1}$ & 0.1693 & 0,4803 & $0,0,1,9$ & $-[0,1.231)$ & $0,06,20$ & $0.3941 n$ & $0.8: 2 n:$ & חסוזחס & n.חים & 0.7474 \\
\hline$-1,405 \%$ & 0.8270 & 0,5963 & 0.1663 & -0.2520 & $-0,0890$ & 0,2293 & 0,5986 & 0,1971 & $-0,2155$ & 0,1322 \\
\hline$-1,2 n 2 ?$ & 0,0590 & $-0,0191$ & 0,2090 & 0,1027 & 0.1194 & 0,5932 & $-0,2541$ & $-0,2690$ & 0,0304 & 0,3260 \\
\hline-0.5392 & -019.2781 & $-0,5055$ & 0,3179 & $-0,0418$ & $-0,4573$ & 1,3987 & 0,8862 & $-0,1479$ & $-0,4037$ & $-0,2426$ \\
\hline$-1.06,35$ & $-10,0004$ & $-0,2735$ & $-0,3366$ & $-0,3045$ & 0.0873 & 1,1429 & 0,4211 & $0,744,7$ & $-0,0792$ & $-0,0981$ \\
\hline-0.1 .025 & $-0,2272 \mathrm{~A}$ & 0,4708 & 0,2130 & $0, ?\{? 6$ & 0,1917 & $-1,1156$ & 0,5545 & 0,0415 & 0,2151 & $-0,2761$ \\
\hline $.9,9457$ & 0.6127 & 0,0815 & 0,6609 & 0,4374 & $-0,1272$ & 0,5190 & $-0,2481$ & $-0,5179$ & 1,0584 & 0,3664 \\
\hline$-0,91755$ & $0,04 \pi 2$ & 0,2003 & 0,0430 & $-0,1304$ & $-0,4194$ & 0,8076 & 0,4903 & 0,1077 & $-0,0116$ & $-0,0596$ \\
\hline$\therefore, 1156$ & $\therefore .2704$ & 0,3001 & $-0,0.750$ & $-0,9115$ & $-0,2093$ & 0,4323 & 0,3196 & $-0,1663$ & $-0,1125$ & $-0,0915$ \\
\hline-0.9730 & 0,3417 & $-0,4404$ & $-0,2253$ & $-0,3952$ & 0,0569 & 0,3399 & 0,5328 & $-0,2552$ & $-0,0133$ & $-0,7193$ \\
\hline$-1,70 r$ & $-0,3027$ & 0,0049 & $-0,1334$ & $-0,0802$ & 0,2121 & 1.2376 & $-0,2912$ & $-0,1617$ & $-0,3253$ & $-0,1905$ \\
\hline$-1.25 n:$ & -0.3975 & 0,3244 & 0,2448 & $-0,22: .3$ & $-0,1127$ & 0,6230 & 0,1766 & 0,3263 & 0,1771 & 0,2666 \\
\hline$-0,9070$ & -0.15 .37 & $-0,2569$ & 0,2380 & $-0,0718$ & 0,1274 & 1,3448 & 0,5559 & $-0,0411$ & $-0,2240$ & $-0,3237$ \\
\hline$-1,39 ?$ & $.9,81 \cap 6$ & $-0,0604$ & -0.2135 & $0,5,735$ & 0.0081 & 1,1214 & 0.8174 & $-0,0702$ & 0.1815 & $-0,4614$ \\
\hline$-1,2550$ & $-0,2658$ & 0,2204 & 0.3205 & -0.2096 & $-0,4548$ & 0,5435 & $-0,0194$ & $0,19 \%$ & $0,+, 1 / 1$ & $0,06,72$ \\
\hline$-\cap, 8342$ & $-0,2276$ & 0,0890 & 0,5028 & 0.4339 & 0,0456 & 0,9243 & 0,5436 & $-0,3825$ & $-0,298.7$ & 0,0697 \\
\hline .0 .0200 & 0,3557 & $-1,3083$ & 0,3055 & $-0,5501$ & $-0,1797$ & $-0,2206$ & 3.4649 & $-0,9$ & 0.5387 & 0,3085 \\
\hline-1.5207 & $-0,1 \Omega 283$ & $-0,1963$ & $0.333 \%$ & $-0,1507$ & $0,387 t$ & 0,4901 & 0,5395 & 0,3580 & -0.3754 & $-0,2960$ \\
\hline-1.24893 & 0,0409 & $-0,4823$ & 0,0839 & $-0,3752$ & $-0,5531$ & 0,6099 & 0,3428 & 0,6141 & 0,7439 & $-0,2: 73$ \\
\hline$\cap, 5456$ & 0.3113 & 0.1993 & $-0,3799$ & $-6,2184$ & 0.0713 & 1,2541 & 0,1683 & $0,62.13$ & $0,589_{4}$ & $-0,5777$ \\
\hline-0.6550 & $-17,4109$ & $-0,0080$ & 0,3489 & 0,7196 & 0,1505 & 1,1059 & $-0,3844$ & $-0,2075$ & -0.8307 & 0,5858 \\
\hline 1.5113 & $-n, 2126$ & $-0,0651$ & $-0,36 ? ?$ & $-0,2050$ & 0,0093 & 1,1495 & $-0,2226$ & $-0,78,00$ & $-0,2: 13$ & - \\
\hline ration & $n, 2011$ & $-1,5192$ & $-0,2181$ & 0,3867 & 0.1051 & 1,1478 & 0,4961 & 0,3528 & $-0,7618$ & $-0,0381$ \\
\hline$-1,4002$ & -0.1260 & 0,5868 & $-0,2352$ & $0,150 \mathrm{c}$ & $0,38,20$ & 0,7484 & $-0,5379$ & $-0,2143$ & 0,0571 & $-0,1015$ \\
\hline $9.96 .3 \%$ & -0.3566 & 0,7703 & 0,3054 & $-0,2611$ & $-0,1886$ & 0,2500 & $-0,3712$ & $-0,0036$ & $-0,2416$ & 0,5132 \\
\hline .03 .3150 & $-n, 7505$ & 0,1249 & $-0,75 \cap 3$ & 0,4727 & 0,0501 & $-0,2159$ & 0.4483 & $-0,8346$ & $-0,6151$ & 0,2262 \\
\hline 1,4758 & -0.1514 & 0,0902 & 0,0739 & $0,18.54$ & $-0,0066$ & 1,3895 & 0,5625 & 0,4266 & $-0,1434$ & $-0,1127$ \\
\hline$\because 189.1$ & $-01,61111$ & 0,6611 & 0,3750 & $0.3: 30$ & 0.3162 & -0.0001 & $-1,7004$ & $-0.100 ?$ & 0.1595 & $0 . C \equiv i_{i}$ \\
\hline$-1,1100$ & $-0,8713$ & 0,2116 & $-0,3228$ & 0.7539 & 0.2716 & 0,7727 & $-0,1122$ & $-0,006 \vdots$ & $-0,4309$ & 0.1615 \\
\hline$-1,35 \%$ & $0,3 n 23$ & 0,4508 & 7,1853 & $-0,1769$ & $-0,6790$ & 0,5459 & 0,7470 & $-0,0294$ & $-0,0991$ & $-0,1188$ \\
\hline$-1,1005$ & $.7,0183$ & 0,0586 & $-0,1841$ & $-0,3585$ & $-0,3002$ & 0,0972 & $-0,1642$ & 0,3463 & 0,3009 & $-0,0282$ \\
\hline$-1,23667$ & 0,2220 & $-0,5601$ & $-0,2982$ & 0,0013 & $-0,018,4$ & 0,3856 & 0,3224 & 0.1528 & $-0,5084$ & $-0,1553$ \\
\hline-0.4267 & 0,3038 & 0,4294 & 0,2581 & $-0,1146$ & $-0,168 ?$ & 1,2388 & 0,3790 & 0,3137 & $0,266,3$ & 0.4393 \\
\hline 0,7039 & 0,5804 & 0,1113 & 0,4878 & $-0,1201$ & $-0,3679$ & 0,9473 & 0,1440 & $-0,2920$ & $-0,2706$ & 0,0535 \\
\hline$-1,6900$ & 0,1224 & 0,2595 & 0,2200 & $-0,0121$ & $-0,4340$ & 0,0245 & $-0,0000$ & $-0,3934$ & 3,0055 & 0,0432 \\
\hline$-1,4009$ & 0,0950 & 0,2772 & $-0,2100$ & $-0,5997$ & $-0,0687$ & $-0,0602$ & $-0,6978$ & 0,2584 & $-0,0767$ & $0,157 ?$ \\
\hline$-1,79 \curvearrowleft ?$ & $-1 ., 1727$ & 1,2278 & 0,5622 & 0,2314 & 0,0885 & 1,4549 & 0,7846 & 0,2563 & 0.1393 & -0.0443 \\
\hline-1.3051 & 1,9215 & $-0,1129$ & 0,4761 & $-0,5990$ & 0,2926 & 1,2214 & 0,0689 & $-0,7068$ & $-0,5432$ & $-0,1784$ \\
\hline$-1,5617$ & 0,4814 & 1,1005 & 1,0485 & $-0,8571$ & $-0,1778$ & 0,2787 & $-0,0267$ & 0,0871 & $-0,1770$ & 0,4289 \\
\hline$\therefore .611 .1$ & 1,0542 & $.0,5768$ & $-0,5 \dot{\sigma} 21$ & $-0,1722$ & $-0,2911$ & 0,6751 & 0,2004 & $-0,4492$ & 0,3191 & 0,5564 \\
\hline$-\ddot{z} .9910$ & 0,1466 & $-0,1753$ & 0,4034 & 0.3225 & $-0,3521$ & 0.7144 & $-0,2190$ & 0.2754 & $-0,5307$ & 0.0334 \\
\hline 2,1359 & $-1,6435$ & $-0,9349$ & 0,1875 & 0,5957 & 0,3264 & 0,7703 & $-0,2249$ & $-0,0970$ & $-0,1082$ & 0.0008 \\
\hline$-1,9080$. & $-0,7132$ & 0,1666 & 0,2374 & 0,0602 & 0,4009 & 0,9670 & 0,7740 & 0,0287 & 0,2615 & 0,2472 \\
\hline$n .9869$ & 0,1714 & 1,2690 & 0,7065 & 0,1551 & 0,4702 & 1,2213 & 0,2875 & $-0,0881$ & 1.1030 & 0,4470 \\
\hline$-2, \ln 6,9$ & 0,1997 & $-0,0890$ & $-0,1567$ & 0,2249 & $-0,4731$ & 0,2464 & 0,9431 & 0,6901 & $-0,2033$ & $-0,1087$ \\
\hline
\end{tabular}

